Rodrigo Rocha Codarin

\title{
Análise do controle glicêmico e de marcadores laboratoriais de função renal para a predição de crescimento fetal em gestantes com diabetes mellitus tipo 1
}

\author{
Dissertação apresentada à Faculdade de \\ Medicina da Universidade de São Paulo \\ para obtenção do título de Mestre em \\ Ciências \\ Programa de Obstetrícia e Ginecologia \\ Orientadora: Profa. Dra. Rossana \\ Pulcineli Vieira Francisco
}

São Paulo 
Dados Internacionais de Catalogação na Publicaçăo (CIP)

Preparada pela Biblioteca da

Faculdade de Medicina da Universidade de Săo Paulo

Creproduçāo autorizada pelo autor

Codarin, Rodrigo Rocha

Análise do controle glicêmico e de marcadores

laboratoriais de funçăo renal para a predição de

crescimento fetal em gestantes com diabetes

mellitus tipo 1 / Rodrigo Rocha Codarin. -- Säo

Paulo, 2017.

Dissertação (mestrado)--Faculdade de Medicina da Universidade de são Paulo.

Programa de Obstetricia e Ginecologia.

Orientadora: Rossana Pulcineli Vieira Erancisco.

Descritores: 1. Gravidez em diabéticas

2. Desenvolvimento fetal/fisiologia 3. Complicaçōes do

diabetes 4. Nefropatias 5. Peso ao nascer 6. Predição

$\mathrm{USP} / \mathrm{EM} / \mathrm{DBD}-475 / 17$ 
Esta dissertação está de acordo com as seguintes normas, em vigor no momento desta publicação:

Referências: adaptado de International Committee of Medical Journals Editors (Vancouver).

Universidade de São Paulo. Faculdade de Medicina. Divisão de Biblioteca e Documentação. Guia de apresentação de dissertações, teses e monografias.

Elaborado por Anneliese Carneiro da Cunha, Maria Julia de A. L. Freddi, Maria F. Crestana, Marinalva de Souza Aragão, Suely Campos Cardoso, Valéria Vilhena. 3a ed. São Paulo: Divisão de Biblioteca e Documentação; 2011.

Abreviaturas dos títulos dos periódicos de acordo com List of Journals Indexed in Index Medicus. 
"Há três caminhos para o fracasso: não ensinar o que se sabe, não praticar o que se ensina, e não perguntar o que se ignora."

- São Beda 


\section{Agradecimentos}

Inicialmente, agradeço a Deus, pela benção de fazer parte de uma família acolhedora e carinhosa, pelos exemplos de pessoas e profissionais que tive durante a vida, pelas oportunidades que tenho e terei, e por Estar ao meu lado e me dar forças e saúde para buscar meus objetivos e minha felicidade.

Ao meus pais, Dr. Olivio Codarin e Dra. Gleisa Maria Rocha Codarin, pelo amor, carinho e cuidados constantes. Essência e estrutura para tudo que sou e serei.

À minha esposa, Dra. Livia Ferraz Accorsi Codarin. Inicialmente, peço desculpas pelos vários episódios em que o meu amor à medicina, ao trabalho e ao ensino, atrapalharam nosso convívio. Obrigado pelo amor, cuidado, gentileza, carinho e cumplicidade característica de nosso relacionamento. Companheira de vida.

Ao meu irmão querido, Dr. Felipe Rocha Codarin, que, da sua maneira, sempre me estimula a tentar ser alguém melhor e crescer.

Aos meus sogros, Sra. Maria Helena Ferraz Accorsi e Sr. Edison Adelino Accorsi, por demonstrarem o real significado de acolhimento em uma nova família.

Aos meus avós paternos e maternos, Luiz e Olivia Codarin, e Expedita e José Rocha, pelo carinho na infância e pelo exemplo de vida, demonstrando que humildade e suor são características essenciais ao homem.

Ao meu Tio Avô, Dr. Benedito Rocha, por também figurar como norte de decência, dedicação ao trabalho e carinho em minha infância.

Ao Prof. Dr. Marcelo Zugaib, por ditar o ritmo, organizar e estruturar e capitanear a evolução da Clínica Obstétrica. Um pilar obstétrico na atualidade. Obrigado pelas oportunidades e estímulo. 
À Profa. Dra. Rossana Pulcineli Viera Francisco, minha "mentora acadêmica", exemplo de profissional dedicado a pesquisa, educação e assistência. Além de tudo: grande amiga e conselheira. Obrigado por ter me convidado, ainda quando residente, para "escutar meu coração" e ficar na Obstetrícia. Obrigado por todos os ensinamentos, principalmente aqueles do processo de tentar fazer de mim um pesquisador. Obrigado pela confiança e oportunidade de, mesmo ainda jovem, me colocar em obrigações e cargos desafiadores.

À Dra. Rafaela Alkmin da Costa, minha "parceira diabética", por ter a honra de, ao seu lado, poder cuidar de gestantes diabéticas tipo 1 com tanta qualidade. Obrigado pela ajuda contínua e amizade.

À Dra. Cristiane de Freitas Paganoti, grande amiga, confidente, perfeccionista, versátil e excelente médica. Obrigado pelas conversas, pelo apoio e incentivo. Pessoas assim nos dão empolgação para continuar na academia.

À Enf. Ana Maria da Silva Sousa, profissional dedicada, extremamente carinhosa com as pacientes e preocupada com o processo de pesquisa. Sem a sua colaboração, com certeza, este trabalho não teria a mesma qualidade.

À Dra. Ana Claudia Souza, colega de pós graduação e diabetes, ex-residente e grande pesquisadora.

À Dra. Fernanda Cristina Ferreira Mikami, amiga, "professora" dos tempos de residência, parceira de plantões, partos e madrugadas sem fim.

À Dra. Maria Rita de Figueiredo Lemos Bortolotto, pela atenção, "adoção" e cuidados desprendidos.

À Dra. Eliane Aparecida Alves, amiga caridosa e gentil, obrigado pelo cuidado comigo. 
À Dra. Fernanda Spadotto Baptista, pela companhia impagável, pelas risadas e preocupações compartilhadas.

À Dra. Renata Lopes Ribeiro, pela amizade, paciência e parceria. Obrigado pelas longas conversas.

À Dra. Marina de Oliveira Gonzales e Dra. Renata Franco Pimentel Mendes, obrigado pelo convívio, ajudas, trabalhos, partos, risadas... Obrigado por me ajudarem no HC e fora dele.

Aos Dr. Carlos Eduardo Czeresnia e Dra. Lucila Pires Evangelista, meus "chefes" da vida privada. Obrigado pelo estimulo constante (e infindável) para os estudos. Obrigado pelas oportunidades de trabalho. Sem vocês, manter-me na vida acadêmica, seria ainda mais difícil.

Aos Dr. Antonio Carlos Bastos Navarro Filho e Dr. Daniel Rolnik, pela ajuda na minha formação no período da residência e pelo companheirismo e amizade desde então.

À Banca da qualificação: Prof. Dr. Mario Henrique Burlacchini de Carvalho, Profa. Dra. Lisandra Stein Bernardes, Profa. Dra. Elaine Christine Dantas Moisés. Além do excelente trabalho e grandes contribuições dadas na qualificação da dissertação, acho que também posso agradecer pela amizade e atenção comigo.

Um agradecimento especial aos participantes e suplentes da banca de defesa que dispensaram seu tempo e conhecimento com a minha formação acadêmica.

Obrigado aos colegas da Clínica Obstétrica do Hospital das Clínicas da Faculdade de Medicina da Universidade de São Paulo. Muito obrigado por poder dividir meus dias com os senhores. Obrigado por tudo que me foi ensinado neste lugar. Tenho muito orgulho de participar disso tudo. 
Aos funcionários da Clínica Obstétrica, obrigado pela ajuda diária, apoio, dicas, e pelo convívio.

À enfermagem da Clínica Obstétrica, pessoas guerreiras, que enfrentam todo o tipo de dificuldade ao nosso lado no cuidado das pacientes, e ainda são gentis e cuidadosas conosco.

Aos Residentes. Confesso que uma enorme parte da minha "empolgação acadêmica" vem do prazer que tenho em compartilhar conhecimentos com pessoas tão jovens e com tanto talento.

Às pacientes, em especial, àquelas com diabetes tipo 1. Este trabalho é fruto da minha vontade de cuidar. Obrigado pela disposição em compartilhar suas informações para realização desta pesquisa. A vida pode ser, muitas vezes, sofrida mas fazer esta caminhada juntos nos faz mais fortes. 


\section{Sumário}

Lista de Tabelas

Lista de Gráficos

Lista de Abreviaturas

Resumo

Summary

1. Introdução ......................................................................... 01

1.1.Diabetes mellitus tipo 1 ......................................... 02

1.2.0 impacto da gestação na diabetes mellitus ....................... 03

1.3. O impacto da diabetes mellitus tipo 1 na gestação .............. 03

1.4. Crescimento fetal em pacientes com DM1 ....................... 05

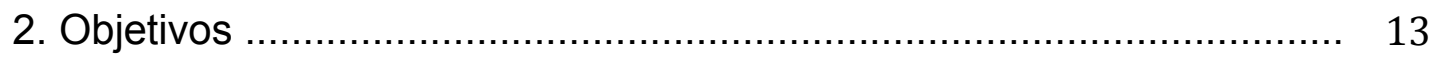

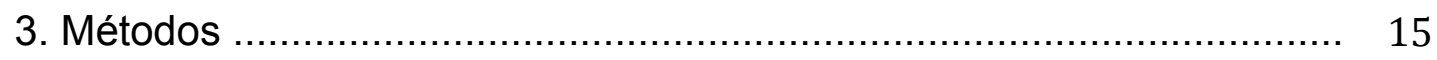

3.1. Casuística .............................................................. 16

3.2. Método....................................................................... 16

3.2.1. Seleção das pacientes .......................................... 16

3.2.1.1. Critérios de Inclusão ................................................ 17

3.2.1.2. Critérios de Exclusão ............................................... 17

3.2.1.3. Tamanho amostral ............................................. 17

3.2.2. Coleta de dados .................................................. 18

3.2.2. Seguimento das gestantes portadoras de DM1 .............. 18

3.2.3. Análise estatística .................................................. 23

3.2.3.1. Formação dos grupos ............................................ 23

3.2.3.2. Variáveis analisadas .............................................. 23

3.2.4. Análise estatística .................................................... 25

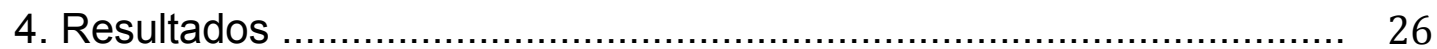

4.1. Características das gestantes no início do pré-natal ........... 28

4.2. Intercorrências clínicas e obstétricas ............................... 29

4.3. Dados do parto ............................................................. 30

4.4. Marcadores laboratoriais e relação com classificação do peso no nascimento

4.4.1. Tempo de coleta dos exames ................................. 32 
4.4.2. Ácido Úrico 33

4.4.3. Creatinina ............................................................. 33

4.4.4. Proteinúria de 24 horas .................................................. 34

4.5. Controle Glicêmico ......................................................... 36

4.5.1. Hemoglobina Glicada ................................................. 36

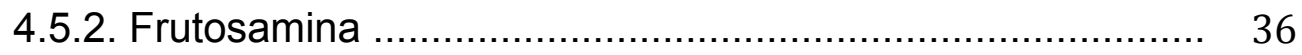

4.5.3. Média glicêmica ....................................................... 37

4.5.4. Porcentagem de Hipoglicemia ....................................... 38

4.5.5. Porcentagem de Hipoglicemia grave ……....................... 39

4.5.6. Porcentagem de Hiperglicemia ....................................... 39

4.5.7. Porcentagem de Hiperglicemia grave ............................. 40

4.6. Análise de fatores preditores do crescimento fetal .............. 41

4.6.1. Primeiro Trimestre ….................................................. 42

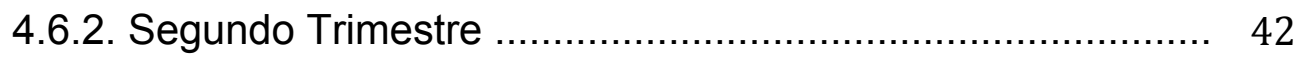

4.6.3. Terceiro Trimestre ........................................................ 43

4.6.3.1. Curva de probabilidade de PIG, AIG e GIG segundo o valor da média glicêmica, fixando-se o valor da creatinina sérica no terceiro trimestre .............................................................. 45

4.6.3.2. Curva de probabilidade de PIG, AIG e GIG segundo o valor da creatinina sérica, fixando-se o valor da média glicêmica no terceiro trimestre ......................................................... 48

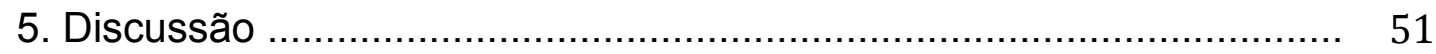

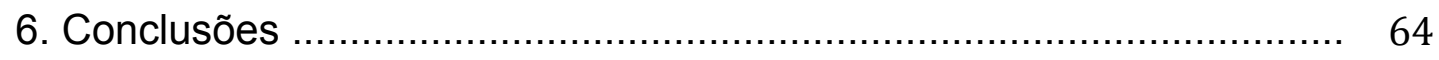

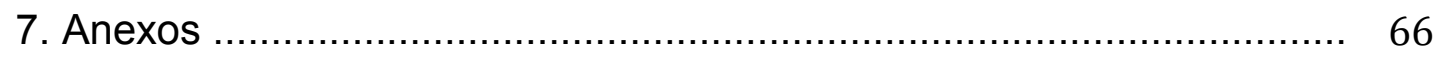

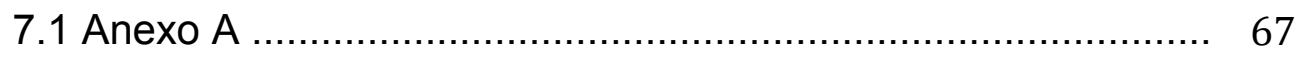

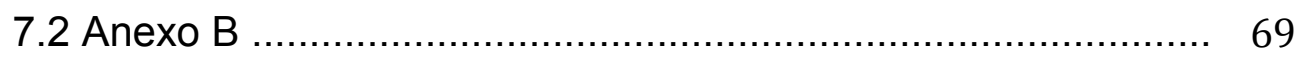

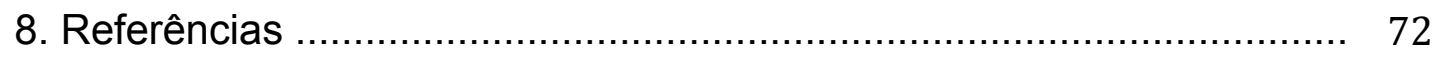




\section{Lista de Tabelas}

Tabela 1. Frequência de PIG de acordo com a presença e tipo de vasculopatia diabética materna

Tabela 2. Recém nascidos grandes para a idade gestacional de acordo com a categorização da $\mathrm{HbA} 1 \mathrm{c}$ com 26 semanas em gestantes com DM1

Tabela 3. Comparação de exames laboratoriais entre gestantes DM1 de acordo com classificação de peso do recém nascido .....

Tabela 4. Valores de normalidade do perfil glicêmico

Tabela 5. Situações particulares e momento de indicação de resolução da gestação

Tabela 6. Distribuição das pacientes com diabetes mellitus tipo 1, nos três grupos de estudo, segundo a classificação do recém nascido pela curva de Fenton et al. - HC-FMUSP 2013 a 2016

Tabela 7. Características das gestantes com diabetes mellitus tipo 1, no início do pré-natal,nos diferentes grupos - HC-FMUSP 2013 a 2016

Tabela 8. Distribuição dos casos de hipertensão arterial crônica, préeclâmpsia, nefropatia, microalbuminúria e retinopatia nos diferentes grupos em gestantes com diabetes mellitus tipo 1 - HC-FMUSP - 2013 a 2016

Tabela 9. Idade gestacional e peso do recém nascido no parto em gestantes com diabetes mellitus do tipo 1 nos grupos estudados - HC-FMUSP - 2013 a 2016

Tabela 10. Via de parto em gestantes com diabetes mellitus do tipo 1 nos grupos estudados - HC-FMUSP - 2013 a 2016

Tabela 11. Idade gestacional da coleta de exames das gestantes com diabetes mellitus tipo 1 - HC-FMUSP - 2013 a 2016

Tabela 12. Variação da dosagem sérica de ácido úrico nos três grupos conforme os trimestres da gestação - HC-FMUSP -2013 a 2016

Tabela 13. Variação da dosagem sérica de creatinina nos grupos estudados conforme os trimestres da gestação - HCFMUSP - 2013 a 2016 
Tabela 14. Variação da dosagem de proteinúria de 24 horas de acordo com a classificação de peso do recém-nascido conforme os trimestres da gestação - HC-FMUSP - 2013 a 2016

Tabela 15. Valores de hemoglobina glicada conforme os trimestres da gestação nos diferentes grupos - HC-FMUSP - 2013 a 2016

Tabela 16. Valores de frutosamina nos trimestres da gestação nos três grupos avaliados- HC-FMUSP - 2013 a 2016

Tabela 17. Média glicêmica nos trimestres da gestação nos grupos estudados - HC-FMUSP - 2013 a 2016

Tabela 18. Porcentagem de hipoglicemias nos trimestres da gestação nos diferentes grupos - HC-FMUSP - 2013 a 2016

Tabela 19. Porcentagem de hipoglicemias graves nos trimestres da gestação nos três grupos estudados- HC-FMUSP - 2013 a 2016

Tabela 20. Porcentagem de hiperglicemias de acordo com a classificação de peso do recém-nascido conforme os trimestres da gestação - HC-FMUSP - 2013 a 2016

Tabela 21. Porcentagem de hiperglicemias grave de acordo com a classificação de peso do recém-nascido conforme os trimestres da gestação - HC-FMUSP - 2013 a 2016

Tabela 22. Ajustes do modelo preditor de alterações de crescimento fetal em gestantes com DM1 para o primeiro trimestre

Tabela 23. Ajustes do modelo preditor de alterações de crescimento fetal em gestantes com DM1 para o segundo trimestre ......

Tabela 24. Ajustes do modelo preditor de alterações de crescimento fetal em gestantes com DM1 para o terceiro trimestre

Tabela 25. Ajustes do modelo preditor de alterações de crescimento fetal de acordo com os valores da média glicêmica glicemia e de creatinina sérica, no terceiro trimestre em gestantes com DM1 


\section{Lista de Gráficos}

Gráfico 1. Curva de probabilidade de crescimento fetal em gestantes com diabetes mellitus tipo 1 , a depender dos níveis de média glicêmica no terceiro trimestre, considerando-se um nível de creatinina no terceiro trimestre de $0,6 \mathrm{mg} / \mathrm{dL}-\mathrm{HC}$ FMUSP - 2013 a 2016

Gráfico 2. Curva de probabilidade de crescimento fetal em gestantes com diabetes mellitus tipo 1 , a depender dos níveis de média glicêmica no terceiro trimestre, considerando-se um nível de creatinina no terceiro trimestre de $1,4 \mathrm{mg} / \mathrm{dL}-\mathrm{HC}$ FMUSP - 2013 a 2016

Gráfico 3. Curva de probabilidade de PIG, AIG e GIG, segundo o valor da creatinina sérica, fixando-se o valor da média glicêmica no terceiro trimestre 


\section{Lista de Abreviaturas}

DM Diabetes mellitus

DM1 Diabetes mellitus tipo 1

DM2 Diabetes mellitus tipo 2

DMG Diabetes mellitus gestacional

GIG recém-nascidos grandes para a idade gestacional

PIG recém-nascido pequeno para a idade gestacional

AIG recém-nascidos com peso adequado para a idade gestacional

HbA1c Hemoglobina glicada

HC- Hospital das Clínicas da Faculdade de Medicina da

FMUSP Universidade de São Paulo

TCLE Termo de Consentimento Livre e Esclarecido

CAPPesq Comissão de Ética para Análise de Projetos de Pesquisa

USG Ultrassonografia

Dextro Glicemia sanguínea capilar

ADA American Diabetes Association

MDDI Múltiplas doses diárias de insulina

SICl Sistema de infusão contínua de insulina

ISSHP International Society for the Study of Hypertension in Pregnancy

$\mathrm{mg} / \mathrm{dL} \quad$ Miligramas por decilitro

g/vol Gramas no volume

$\mu \mathrm{mol} / \mathrm{L} \quad$ Micromol por litro

HDL High Density Lipoproteins

LDL Low Density Lipoproteins

$\mathrm{Kg} / \mathrm{m} 2 \quad$ Quilogramas por metro quadrado

g Gramas

IMC Índice de massa corpórea

CGMS Real-time continuous glucose monitoring 
Codarin RR. Análise do controle glicêmico e de marcadores laboratoriais de função renal para a predição de crescimento fetal em gestantes com diabetes mellitus tipo 1 [Dissertação]. São Paulo: Faculdade de Medicina, Universidade de São Paulo; 2017.

\section{Resumo:}

Introdução: O Diabetes mellitus tipo 1 (DM1) cursa com produção ausente ou irrisória de insulina e é a forma responsável pelos casos mais graves de distúrbios glicêmicos. O DM1 exerce forte influência sobre o crescimento fetal. Enquanto a hiperglicemia estimula o crescimento fetal devido à hiperinsulinemia, nas pacientes com vasculopatias a placentação inadequada pode levar o feto à restrição. Objetivos: identificar alterações de crescimento fetal e avaliá-las quanto a sua associação com o controle glicêmico materno e de marcadores laboratoriais de função renal. Métodos: foram avaliadas, de forma prospectiva em coorte observacional, 60 gestantes com DM1 que iniciaram o pré-natal no primeiro trimestre. A associação entre a classificação de peso ao nascimento com as seguintes variáveis foi analisada: média glicêmica, frequência de hipo e hiperglicemia, frequência de hipo e hiperglicemia grave, hemoglobina glicada, frutosamina, ácido úrico, creatinina e proteinúria de 24 horas. A predição do crescimento fetal também foi estudada. Resultados: Desvios do crescimento fetal em pacientes com DM1 ocorreram em $41 \%$ dos casos $(n=25)$. Observou-se que $10 \%$ das gestações resultaram em PIG $(n=6)$ e 31\%, em GIG $(n=19)$. Níveis aumentados de média glicêmica ( $p=0,006)$, baixa frequência de hipoglicemias $(p=0,027)$ e alta frequência de hiperglicemias $(p=0,014)$ se associaram a GIG no terceiro trimestre. Em todos os trimestres, valores séricos mais elevados de ácido úrico, creatinina e proteinúria de $24 \mathrm{hs}$, se associaram de maneira significativa, ao grupo PIG. Foi construído um modelo, com taxa de acerto de $80.3 \%$, para a predição de crescimento fetal com os valores de terceiro trimestre da média glicêmica e da creatinina. Conclusões: Foram identificadas variáveis relacionadas ao controle glicêmico materno e à marcadores laboratoriais de função renal que se associaram a alterações no 
crescimento fetal. Usando algumas dessas variáveis foi possível construir um modelo para predição do crescimento fetal com boa acurácia.

Descritores: gravidez em diabéticas; desenvolvimento fetal/fisiologia; complicações do diabetes; nefropatias; peso ao nascer; predição 
Codarin RR. Analysis of glycemic control and renal function laboratory markers in pregnant women with type 1 diabetes mellitus for prediction of fetal growth [Dissertation]. São Paulo: "Faculdade de Medicina, Universidade de São Paulo"; 2017.

\section{Summary:}

Introduction. Diabetes mellitus type 1 (DM1) is described as absent or negligible production of insulin and it is responsible for the most severe cases of glycemic disorders. DM1 has a strong influence on fetal growth. In pregnant women the hyperglycemia stimulates fetal growth, and the vasculopathy influences the placentation process, which may lead to growth restriction. Objective. To identify fetal growth disorders and their association with maternal glycemic control and laboratory markers of renal function. Methods. Sixty pregnant women with DM1 were prospectively followed from the first trimester in an observational cohort. The association between birthweight classification with the following parameter were investigated: glycemic mean, frequency of hypo and hyperglycemia, frequency of severe hyper and hypoglycemia, glycated hemoglobin, fructosamine, uric acid, creatinine and proteinuria of 24 hours. The prediction of fetal growth was also investigated. Results. Abnormal fetal growth was observed in $41 \%(n=25)$. Large for gestational age (LGA) was observed in $31.7 \% \quad(n=19)$ and small for gestational age $(S G A)$ in $10 \%(n=6)$. High values of glycemic mean $(p=$ $0.006)$, low frequency of hypoglycemia $(p=0.027)$ and high frequency of hyperglycemia $(p=0.014)$ were significantly associated with LGA fetal growth in the third trimester. In all trimesters, the SGA fetal growth was significantly associated with higher serum values of uric acid, creatinine and proteinuria of 24 hours. The prediction model for fetal growth, using values of glycemic mean and creatinine, was significant in the third trimester with an accuracy of $80.3 \%$. Conclusions. The maternal glycemic control and the laboratory markers of renal function associated with the fetal growth disorders in pregnancies with DM1 were identified. Using these parameters it was possible to predict with a good accuracy the fetal growth in DM1. 
Descriptors: pregnancy in diabetics; fetal development /physiology; diabetes complications; kidney diseases; birth weight; forecasting 


\section{Introdução}




\section{Introdução}

\subsection{Diabetes mellitus tipo 1}

O Diabetes mellitus (DM) representa uma alteração no metabolismo de carboidratos, resultando em hiperglicemia por defeitos na produção e/ou ação da insulina. ${ }^{1}$ Pode ser classificado de acordo com seu comportamento clínico e sua fisiopatologia em: tipo 1 (DM1), tipo 2 (DM2), diabetes gestacional (DMG) e outras formas de diabetes. ${ }^{2,3}$

Atualmente, a hiperglicemia é o fator clínico mais frequente durante a gestação. Estima-se que 0,2 a $0,5 \%$ das pacientes com diagnóstico de alguma forma de diabetes durante a gravidez apresentem DM1. ${ }^{3-5}$

Sua prevalência é geograficamente variável, o que pode sugerir a presença de componente ambiental em sua etiologia. Considerando os números mundiais, sua incidência vem aumentando 3 a $4 \%$ ao ano. No Brasil, os estudos populacionais relacionados ao diagnóstico e à epidemiologia do DM1 são escassos. A incidência descrita varia de 1,8 a 12,7 casos por 100.000 habitantes por ano. ${ }^{6-8}$

O DM1 caracteriza-se por doença imunomediada decorrente da destruição das células beta-pancreáticas produtoras de insulina, cursando com produção ausente ou irrisória de insulina e é a forma responsável pelos casos mais graves de distúrbios glicêmicos. ${ }^{9}$

A utilização de insulina exógena mudou o paradigma dessa doença extremamente grave e com péssima expectativa de vida no começo do século passado. Usualmente, com apresentação na infância, tal terapêutica permitiu às pacientes alcançarem a idade reprodutiva, sendo hoje considerada "essencial à vida" nesse grupo. ${ }^{9}$ 


\subsection{O impacto da gestação no diabetes mellitus}

As adaptações fisiológicas endócrinas acometem todas as principais glândulas do organismo durante a gestação. Associa-se a tais mudanças o surgimento de um novo órgão com enorme importância endócrina: a placenta. Sua relação com os demais órgãos do sistema endócrino se dá tanto devido à produção de hormônios similares aos maternos, como a de hormônios placentários específicos. ${ }^{10}$

A gravidez, fisiologicamente, apresenta grande impacto no metabolismo glicídico. A produção de hormônios anti-insulínicos e contra regulatórios pela placenta modifica a resistência insulínica e altera seu metabolismo. ${ }^{11,12}$

Classicamente, pode-se dividir a gestação em duas fases: anabólica e catabólica. Durante a fase anabólica, observa-se aumento na lipogênese, na glicogênese hepática e na transferência de glicose para o feto, acarretando redução da glicemia basal e de jejum. Na fase catabólica, o metabolismo glicêmico visa suprir o feto com glicose e aminoácidos, enquanto utiliza ácidos graxos livres e cetonas como substrato materno. Vários são os fatores relacionados a tal mudança, por exemplo: hormônio lactogênio placentário, prolactina, estrogênio, progesterona, cortisol, leptina, fator de necrose tumoral alfa e resistina. Com a sobrecarga imposta pela gestação, as pacientes portadores de DM1 mudam o padrão de resistência insulínica, gerando notável descontrole glicêmico. ${ }^{5}$

\subsection{0 impacto do diabetes mellitus tipo 1 na gestação}

O DM1 relaciona-se a piores resultados perinatais. A associação entre a piora do controle glicêmico e eventos adversos na gestação já era aventada desde $1892 .{ }^{13}$ Abortamentos, malformações fetais, alterações no crescimento fetal, macrossomia, sofrimento e óbito fetais, além de complicações maternas 
como aumento da frequência de síndromes hipertensivas e cetoacidose diabética, são classicamente relacionadas a essa doença. ${ }^{4,14}$

As malformações fetais associadas ao DM1 derivam de um provável processo oxidativo decorrente da hiperglicemia, durante o período de organogênese, nas primeiras semanas de gestação. Em 1978, Pedersen e Mølsted-Pedersen ${ }^{15}$ já identificaram o diabetes pré-gestacional como um fator teratogênico, em estudo que acompanhou 949 filhos de mães diabéticas, com taxa de malformação de $8,2 \%$.

Em 1954, Pedersen ${ }^{16}$ propõe, pela primeira vez, o mecanismo fisiopatológico para as alterações do diabetes no resultado perinatal. Tal hipótese serve de base para o atual entendimento da interação entre a hiperglicemia e a gestação. Uma vez que a glicose atravessa a placenta por difusão facilitada, traduzindo a hiperglicemia materna em hiperglicemia fetal, gera-se hiperinsulinemia fetal. Esse hormônio atua como estimulador do crescimento fetal levando a recém-nascidos grandes para a idade gestacional (GIG) elou macrossômicos (peso $\geq 4.000 \mathrm{~g}$ ). A hiperglicemia fetal também acabaria por gerar diurese osmótica, causando aumento da quantidade de liquido amniótico. A hiperdistensão uterina resultante do crescimento fetal exagerado e da diurese osmótica propiciaria a prematuridade.

A hiperglicemia fetal é promotora de um desvio na curva de dissociação do oxigênio. A hemoglobina glicada fetal torna-se mais ávida pelo oxigênio,resultando em estado hipóxico relativo que estimula a policitemia. Esse processo é o responsável pela icterícia neonatal (por hemólise, após o nascimento), pela acidemia fetal (derivada de respiração celular anaeróbia) e por eventos trombóticos fetais que podem levar ao óbito. ${ }^{17}$ Jovanovic e Nakai $^{18}$ descrevem que, até meados dos anos 80 , mesmo com o uso de insulina, a taxa de mortalidade perinatal, nessa população, era de aproximadamente 25 a $30 \%$.

Associa-se ainda ao DM, durante a gestação, a maior frequência de desconforto respiratório ao nascimento. A hiperinsulinemia fetal age como fator contrarregulador da produção endógena de glucagon, catecolaminas e cortisol. A redução dessas concentrações, consequentemente, diminui o estímulo à produção de surfactante nos pulmões fetais, aumentando a frequência de desconforto respiratório. ${ }^{10}$ 
Além dessas complicações relacionadas à hiperglicemia materna, na população de gestantes com DM1, a vasculopatia materna pode levar à insuficiência placentária, ampliando o leque das complicações perinatais nessas pacientes, inclusive levando à restrição de crescimento fetal e todas as suas consequências. ${ }^{16,19-22}$

\subsection{Crescimento fetal em pacientes com DM1}

Uma complicação habitual nas gestantes com DM1 são as alterações de crescimento fetal. Nas pacientes portadoras de DM1 com vasculopatia, a placentação inadequada pode levar à restrição de crescimento fetal ${ }^{4,9,10,23-}$ 27. Por outro lado, como a glicose atravessa a placenta de forma livre e a insulina materna só o faz quando ligada a algum anticorpo lgG, o aumento de aporte glicêmico proporcionado ao feto pela glicemia materna aumentada é o responsável por estímulo pancreático fetal e consequente produção de insulina, outros hormônios e fatores anabólicos.

Howarth et al. ${ }^{28}$, em 2007, em estudo retrospectivo, analisaram os dados de parto de 138 mulheres com DM1, relacionando a presença de vasculopatias (definida como presença de alteração em exame de fundo de olho, ou proteinúria acima de $300 \mathrm{mg} / \mathrm{dL}$ ou hipertensão arterial crônica) ao peso de nascimento e pré-eclâmpsia. A presença de vasculopatias foi considerada como fator protetor para macrossomia (OR 0,46; IC95\% 0,224 0,928 ) e preditor de recém-nascido pequeno para a idade gestacional (PIG) (OR 6,0; 1,54-23,33).

Haeri et al. ${ }^{29}$, em 2008, em análise de dados de diabéticas que foram acompanhadas na University of Cincinnati, encontraram associação entre a presença de vasculopatia e PIG. A Tabela 1 demonstra os achados desse estudo. Observa-se que a nefropatia foi a vasculopatia mais frequente nessa população, ocorrendo de forma isolada ou associada à nefropatia em 64/261 $(24,52 \%)$ da população. 
Tabela 1 - Frequência de PIG de acordo com a presença e tipo de vasculopatia diabética materna

\begin{tabular}{lccccc}
\hline & $\begin{array}{c}\text { Sem } \\
\text { vasculopatia }\end{array}$ & $\begin{array}{c}\text { Retinopatia } \\
\text { proliferativa }\end{array}$ & Nefropatia & $\begin{array}{c}\text { Nefro e } \\
\text { retinopatia }\end{array}$ & p \\
\hline Total & 181 & 16 & 40 & 24 & \\
\cline { 2 - 6 } PIG & $3(2)$ & $2(12)$ & $2(5)$ & $4(17)$ & .001 \\
n (\%) & & & & & \\
\hline
\end{tabular}

PIG - Recém-nascido pequeno para a idade gestacional

FONTE: Adaptado de Haeri et al. ${ }^{29}$

Buscando também avaliar o impacto da vasculopatia no resultado perinatal, Durackova et al. ${ }^{30}$, em 2017, realizaram análise retrospectiva de 118 gestantes com DM1. Nessa amostra, os autores não encontraram diferença significativa entre a frequência de GIG $(63,3 \%$ no grupo com vasculopatia $\times 54 \%$ no grupo sem vasculopatias) ou PIG (3,63\% no grupo com vasculopatia x 4,76\% no grupo sem vasculopatias). Nota-se, portanto, divergência na literatura, sobre os efeitos da vasculopatia no crescimento fetal, justificando-se a necessidade de mais estudos sobre o tema.

Se a vasculopatia é associada à redução do crescimento fetal por alguns autores, outros concentram-se em analisar se o controle glicêmico pode ser associado à ocorrência de desvios do crescimento fetal (fetos grandes ou pequenos para idade gestacional).

Para a avaliação do controle glicêmico, vários parâmetros têm sido estudados como: HBA1C, média glicêmica, porcentagem de hipoglicemias e de hiperglicemias. Porém, ainda há dúvidas em relação à importância dos parâmetros avaliados e também quanto à relevância de cada trimestre da gestação na determinação do crescimento fetal.

Mello et al. $^{31}$, em 2000, realizaram estudo comparando as médias glicêmicas no segundo e terceiro trimestres da gestação, categorizadas em maiores ou menores que $95 \mathrm{mg} / \mathrm{dL}$, de pacientes com DM1 e as características antropométricas dos seus recém-nascidos. Os autores relataram que as pacientes com média glicêmica mais alta apresentavam maior frequência de GIG $(37,8 \%$ se a média glicêmica fosse mais alta 
somente no segundo trimestre e $54,2 \%$ se o fosse em ambos os trimestres avaliados).

Em 2007, Herranz et al. ${ }^{32}$ avaliaram 73 gestantes com DM1, excluídos os casos de PIG, objetivando encontrar quais parâmetros glicêmicos estariam correlacionados a recém-nascidos GIG. Nesse estudo, a frequência de GIG e macrossomia foi de $50,7 \%$ e $47,9 \%$ respectivamente. A média glicêmica e a frequência de hiperglicemias, em todos os trimestres, foram maiores no grupo GIG, assim como a média glicêmica pré-prandial e $\mathrm{HbA} 1 \mathrm{C}$, no terceiro trimestre, e a média glicêmica pós-prandial, no segundo e terceiro trimestres.

Aschwald et al. ${ }^{24}$, em 2009, analisaram a correlação do controle glicêmico de 70 gestantes com DM1 com a frequência de GIG. Para tal propósito, dividiram-nas em diversos períodos gestacionais (7-10, 11-15, 16 19 , 20-24, 25-28, 29-32 e 33-38 semanas). Os autores demonstram frequência de GIG de $57 \%(4,3 \pm 0,4 \mathrm{Kg})$ e de fetos adequados para a idade gestacional de $43 \%(3,2 \pm 0,4 \mathrm{Kg})$. Nesse estudo, a porcentagem de valores glicêmicos pré-prandiais acima da meta, entre 11-15, 25-28 e 29-32 semanas, e com todo o controle glicêmico, entre 33-38 semanas, relacionouse com a ocorrência de GIG. Os autores concluíram ser o percentual de valores glicêmicos pré-prandiais alterados o principal fator preditor para GIG.

Persson et al. ${ }^{33}$, em 2011, em estudo populacional observacional sueco, comparando 3.705 filhos de pacientes com DM1 com a população geral, relatam frequência de GIG de $47,3 \%$ no primeiro e $9,9 \%$ no segundo grupo. Os recém-nascidos foram classificados como PIG em 3\% das pacientes com DM1 frente a 9,1\% na população geral.

Damm et al. ${ }^{25}$, em 2014, em reanálise de estudo envolvendo 350 gestantes com DM1, encontraram correlação entre HbA1c aumentada, picos glicêmicos pré e pós-prandiais, albuminúria no primeiro trimestre e piora nos resultados perinatais. No terceiro trimestre, a frequência de GIG e de macrossomia (88 nascimentos [34,24\%]) foi maior na presença de glicemia plasmática acima de 198 mg/dL (Grupo GIG:30 casos [35\%] x Grupo Não GIG:29 casos [17\%]; $p=0,002)$. A porcentagem de glicemias de jejum menor que $70 \mathrm{mg} / \mathrm{dL}$ ou maior que $126 \mathrm{mg} / \mathrm{dL}$ se relacionou à frequência mais elevada de GIG (Grupo GIG média 51,9\% x Grupo Não GIG média 43,9\%; $p=0,004)$. 
Feitosa e Andrade ${ }^{34}$, no Brasil, em 2014, avaliaram parâmetros alternativos para monitorar a glicemia em portadoras de diabetes na gestação. Os autores compararam a frutosamina sérica aos parâmetros do automonitoramento glicêmico nos 14 dias que antecederam a coleta da frutosamina em 47 gestantes portadoras de diabetes (3 pacientes [7,9\%] com DM1, 20 pacientes [52,6\%] com DM2 e 15 pacientes [39,5\%] com DMG). A comparação entre as mães dos recém-nascidos com peso adequado (AIG) $(66,7 \%)$ ou grandes ao nascer $(22,2 \%)$ com as genitoras que tiveram neonatos pequenos para a idade gestacional $(11,1 \%)$ revelou que as últimas tiveram menor média glicêmica (105 vs. 114 e $119 \mathrm{mg} / \mathrm{dL}, \mathrm{p}<0,05)$ e maior percentual de hipoglicemias (11 vs. 0e 0\%, p < 0,05), mesmo com frutosamina dentro dos valores de referência (242 - PIG vs. 218 - AIG e 213 GIG $\mu \mathrm{mol} / \mathrm{l})$.

Maresh et al. ${ }^{35}$, em 2015, em estudo prospectivo com 725 pacientes com DM1 do Diabetes and Pre-eclampsia Intervention Trial, categorizaram e analisaram marcadores glicêmicos no primeiro e no segundo trimestre. Nesse estudo, níveis de $\mathrm{HbA} 1 \mathrm{c}$ entre 6 e 6,4\% com 26 semanas de gestação se correlacionaram com a maior probabilidade de GIG, enquanto níveis entre 6,5 e 6,9\% associaram-se a risco aumentado de prematuridade, hipoglicemia neonatal e resultado perinatal adverso (odds ratio 3,2 ; intervalo de confiança de $95 \%$ - 1,3 a 8,0). Tais riscos correlacionavam-se de forma diretamente proporcional ao aumento da HbA1c. A análise das variáveis com 34 semanas não demonstrou correlação nesse estudo. Os resultados desse estudo são melhores demonstrados na tabela 2. 
Tabela 2-Recém-nascidos grandes para a idade gestacional de acordo com a categorização da hemoglobina glicada com 26 semanas em gestantes com DM1

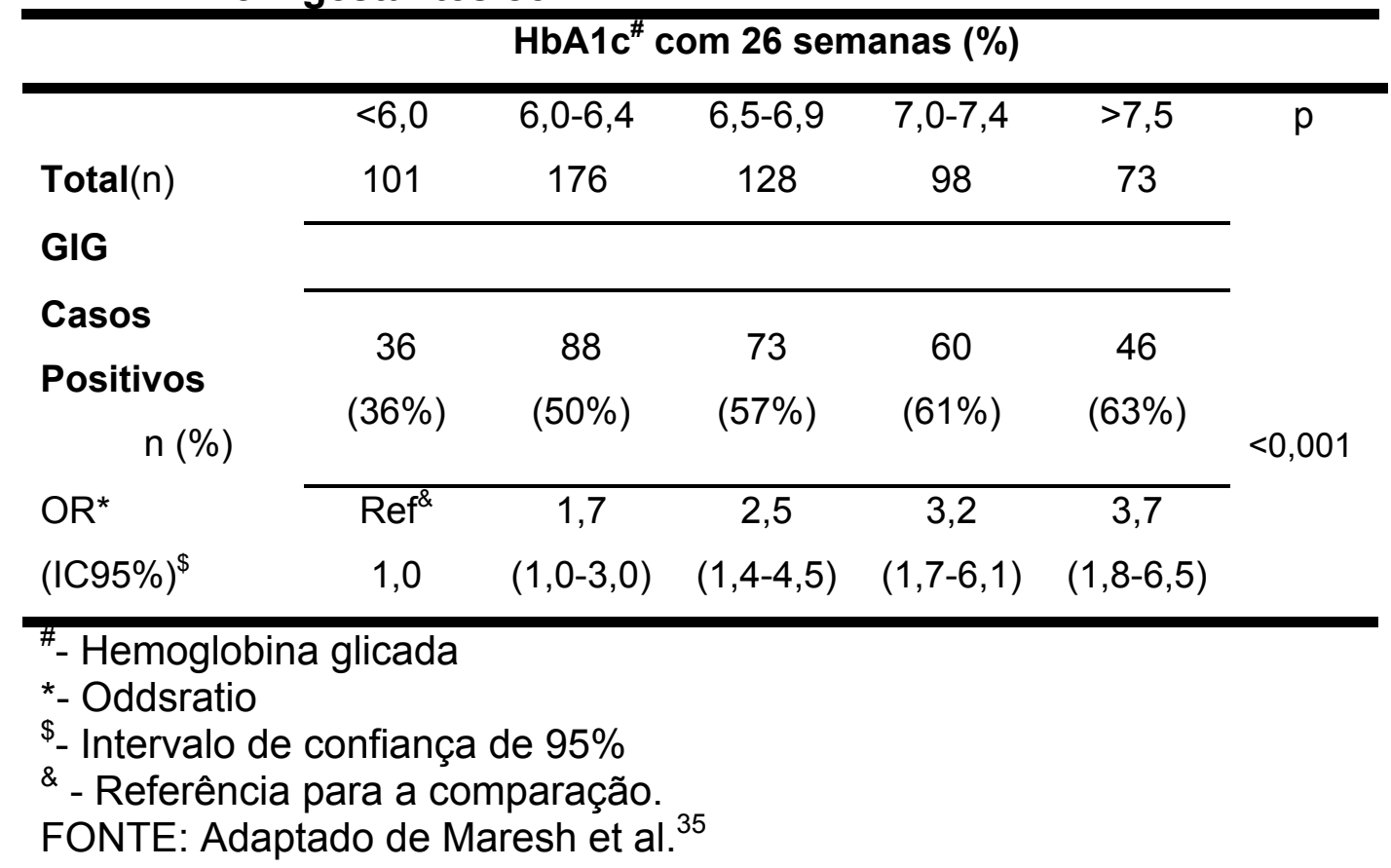

Cahillet al. ${ }^{36}$, em 2016, em coorte prospectiva, compararam 301 pacientes com DM (97 DMG e 204 DM pré-gestacional) para avaliar a associação da frutosamina, $\mathrm{HbA} 1 \mathrm{c}$ e glicemia de jejum com resultados perinatais adversos. Nessa amostra, 49 pacientes $(16,3 \%)$ evoluíram com macrossomia, sendo mais frequente em filhos de mães com DM prégestacional $(22,7 \times 13,2 \%, p=0,04)$. A HbA1c de terceiro trimestre, quando acima de 8,0\%, associou-se significativamente com aumento de risco de morbidade e macrossomia (risco relativo $=4,29$; intervalo de confiança de $95 \%=1,62-11,3)$.

Mehta et al. ${ }^{37}$, em 2016, em estudo retrospectivo, analisaram os dados de 302 gestantes com DM1, associando o peso placentário aos valores de hemoglobina glicada (categorizados como maiores ou menores de $8,5 \%$ ) e a frequência de GIG. Somente em pacientes com $\mathrm{HbA} 1 \mathrm{C}$ elevada no primeiro trimestre foi encontrada associação significativa entre o peso placentário e a frequência de GIG (intervalo entre primeiro e quarto quartil do peso placentário OR $=9.56$, IC95\% 4,14-22,08). Tal associação não se repetiu, nem com outros padrões de controle glicêmico, nem no segundo e terceiro trimestres. 
Gupta et al. ${ }^{38}$, em 2017, também em estudo retrospectivo com 17 anos de duração, tentaram analisar, por meio de métodos estatísticos, parâmetros de glicemia capilar de 199 gestantes com DM1 e compará-los trimestralmente como "medidas repetidas", com a frequência de desfecho GIG e AIG. A frequência de GIG nesaa população foi de $43 \%$. Os autores relatam ter encontrado padrões de comportamento glicêmico diferentes entre os desfechos analisados, sendo que as pacientes do grupo GIG apresentaram diminuição mais acentuada nos níveis de glicemia capilar quando comparadas ao grupo AIG.

Gutaj et al. ${ }^{39}$, também em 2017, avaliaram trimestralmente, de maneira prospectiva, os valores de colesterol e frações em 114 gestantes com DM1. Nessa amostra, a frequência de GIG foi de 26,3\% e nenhum caso evoluiu com PIG. Encontrou-se associação entre recém-nascidos GIG: no primeiro trimestre, níveis mais baixos de HDL e mais elevados de triglicérides; no segundo trimestre, níveis mais baixos de HDL e mais elevados de $\mathrm{HbA1C}$; e no terceiro trimestre, níveis mais baixos de $\mathrm{HDL}$ e mais elevados de $\mathrm{HbA} 1 \mathrm{C}$ e triglicérides. Os resultados desse estudo são melhores demonstrados na tabela 3. 
Tabela 3 - Comparação de exames laboratoriais entre gestantes DM1 de acordo com classificação de peso do recém-nascido.

\begin{tabular}{|c|c|c|c|c|}
\hline & & $\mathrm{AIG}^{*}$ & $\mathbf{G I G}^{\&}$ & $\mathbf{p}$ \\
\hline \multirow{5}{*}{$\begin{array}{l}\text { HbA1C } \\
(\%)\end{array}$} & & $\mathrm{n}=84$ & $n=30$ & \\
\hline & \multicolumn{4}{|c|}{ Mediana (intervalo interquartil) } \\
\hline & $1^{\circ}$ trimestre & $6.2(5.8-7.2)$ & $6.9(6.1-7.6)$ & 0,1 \\
\hline & $2^{\circ}$ trimestre & $5.4(5.1-5.7)$ & $5.8(5.6-6.1)$ & 0,0002 \\
\hline & $3^{\circ}$ trimestre & $5.7(5.5-6.2)$ & $6.2(5.9-6.6)$ & 0,0015 \\
\hline \multirow{3}{*}{$\begin{array}{c}\mathrm{HDL}^{\$} \\
(\mathrm{mg} / \mathrm{dL})\end{array}$} & $1^{\circ}$ trimestre & $77(65-85)$ & $63(59-72)$ & 0,0012 \\
\hline & $2^{\circ}$ trimestre & $90(80-103)$ & $84(69-97)$ & 0,05 \\
\hline & $3^{\circ}$ trimestre & $80(69-95)$ & $71(56-86)$ & 0,03 \\
\hline \multirow{3}{*}{$\begin{array}{c}\text { Triglicérides } \\
\text { (mg/dL) }\end{array}$} & $1^{\circ}$ trimestre & $23(20-30)$ & $29(22-37)$ & 0,04 \\
\hline & $2^{\circ}$ trimestre & $54(43-67)$ & $61(43-76)$ & 0,27 \\
\hline & $3^{\circ}$ trimestre & $90(76-113)$ & $101(89-137)$ & 0,04 \\
\hline
\end{tabular}

* - Adequado para a idade gestacional

\& - Grande para a idade gestacional

\# - Hemoglobina Glicada

\$ - High Density Lipoproteins

Fonte: Adaptado de Gutaj et al. ${ }^{39}$

Finalmente, ao analisar a literatura médica sobre o crescimento fetal em pacientes com DM1, alguns fatores relevantes devem ser ressaltados: a possibilidade de relação entre as vasculopatias e a restrição de crescimento fetal, e também a influência do controle glicêmico na determinação desse crescimento. Se por um lado, a vasculopatia é algo determinado por fatores relacionados à doença materna, sendo a nefropatia uma das mais frequentes manifestações dessa complicação, o controle glicêmico poderá ser otimizado com o objetivo de refrear o crescimento fetal, visto que configura como ponto de partida de seu mecanismo fisiopatológico. Entretanto, a literatura é escassa e inconclusiva em definir qual seria o parâmetro apropriado para a avaliação do controle glicêmico e, especialmente, sobre a sua relação com o crescimento fetal e com a presença de nefropatia. ${ }^{38}$

Uma vez que, em gestantes com DM1, o descontrole glicêmico figura como ponto central das alterações de crescimento fetal, a presença de nefropatia é frequente e passível de ser avaliada e quantificada por exames laboratoriais; e visto que a literatura específica para essa população é 
escassa, torna-se necessário avaliar a relação entre o controle glicêmico e os marcadores laboratoriais de nefropatia e a ocorrência de alterações no crescimento fetal. 


\section{Objetivos}




\section{Objetivos}

O presente estudo que avaliou gestações de pacientes portadoras de diabetes mellitus tipo 1 , nos diferentes trimestres da gestação, teve como objetivos:

Identificar as alterações de crescimento fetal dessa população;

Avaliar a presença de associação do controle glicêmico materno e de marcadores laboratoriais de função renal com o crescimento fetal. 


\section{Métodos}




\section{Métodos}

\subsection{Casuística}

Foram avaliadas, de forma prospectiva em coorte observacional, gestantes com diabetes tipo 1 , que iniciaram o pré-natal, no primeiro trimestre, na Clínica Obstétrica do Hospital das Clínicas da Faculdade de Medicina da Universidade de São Paulo (HC-FMUSP), entre janeiro de 2013 e outubro de 2016. A inclusão no estudo deu-se após análise dos critérios de inclusão, explicação sobre o projeto de pesquisa e assinatura do Termo de Consentimento Livre e Esclarecido (TCLE) aprovado pela Comissão de Ética para Análise de Projetos de Pesquisa (CAPPesq) da Diretoria Clínica do hospital (protocolo de pesquisa número 9034/2013). As gestantes com idade menor que 18 anos tiveram seus TCLE assinados também por seu responsável legal. As pacientes tiveram assegurado seu direito de assistência à saúde, independentemente da participação no estudo.

\subsection{Método}

\subsubsection{Seleção das pacientes}

Foram selecionadas todas as pacientes que procuraram o serviço de pré-natal de alto risco da Clínica Obstétrica do HC-FMUSP no período da pesquisa e que se enquadravam nos critérios de inclusão abaixo relacionados. 


\subsubsection{Critérios de Inclusão}

- Gestação tópica e única,

- Diabetes tipo 1,

- Início do pré-natal, na Clínica Obstétrica do HC-FMUSP, no primeiro trimestre de gestação (idade gestacional até 13 semanas e 6 dias confirmada por ultrassonografia),

- Concordância com o termo de consentimento livre e esclarecido.

\subsubsection{Critérios de Exclusão}

Foram excluídas as pacientes que durante o período de estudo apresentaram:

- Abortamento,

- Perda de segmento ou abandono do pré-natal,

- Diagnóstico de malformações congênitas durante o prénatal ou no período pós-natal,

- Dosagem de Peptídeo C normal ou aumentada.

\subsubsection{Tamanho amostral}

Optou-se por amostra de conveniência com a inclusão de todas as pacientes diabéticas tipo 1 que iniciaram o pré-natal na Clínica Obstétrica do HC-FMUSP e obedeciam aos critérios de inclusão e exclusão. 


\subsubsection{Coleta de dados}

Os dados foram coletados e informatizados em base de dados Microsoft ${ }^{\circledR}$ Office Access ${ }^{\circledR}$ do Setor de Endocrinopatias e Gestação da Clínica Obstétrica do Hospital das Clínicas da Faculdade de Medicina da Universidade de São Paulo.

\subsubsection{Seguimento das gestantes portadoras de DM1}

O seguimento das gestantes foi feito de acordo com o protocolo clínico assistencial vigente da Clínica Obstétrica do HC-FMUSP para gestantes com DM1. ${ }^{40}$

O acompanhamento da gestante com DM tipo 1 foi realizado com retornos semanais ou quinzenais. No primeiro contato com a paciente, realizou-se avaliação geral, com anamnese e exame físico detalhados, bem como solicitação de exames complementares e de avaliação fetal. Os pontos chaves do acompanhamento estão descritos a seguir:

AVALIAÇÃO INICIAL

- Orientação educacional sobre manejo do DM na gestação e risco de complicações decorrentes do descontrole glicêmico: importância do controle glicêmico, mudanças fisiológicas da glicemia na gestação, impacto do diabetes na gravidez e suas complicações perinatais e de vida futura;

- Idade de início do DM e avaliação da compatibilidade da história da paciente com o quadro clínico de pacientes com DM1;

- Hábitos nutricionais e atividade física; 
- $\quad$ Avaliação quanto ao controle glicêmico prévio à gestação;

- Medicações utilizadas;

- Frequência/gravidade dos episódios de hipoglicemia;

- Complicações do DM;

- Antecedentes obstétricos.

\section{AVALIAÇÃO DE LESÕES EM ÓRGÃOS-ALVO}

- $\quad$ Avaliação de fundo de olho com equipe da oftalmologia;

- $\quad$ Avaliação odontológica;

- Eletrocardiograma e Ecocardiogramatranstorácico;

- Avaliação de função renal com dosagem trimestral de ureia, creatinina, microalbuminúria e proteinúria de $24 \mathrm{~h}$.

\section{EXAMES COMPLEMENTARES}

Dosagem trimestral de:

- Hemoglobina glicada

- Frutosamina

- Urocultura

- Ácido úrico

- Creatinina

- $\quad$ Proteinúria de $24 \mathrm{hs}$

Dosagem inicial de:

- $\quad$ Perfil lipídico

- $\quad$ Peptídeo C e glicemia sérica

\section{AVALIAÇÃO FETAL}

- Ultrassonografia (USG) morfológica de $1^{\circ}$ e $2^{\circ}$ trimestres

- USG obstétrico mensal a partir de 26 semanas 
- $\quad$ Ecocardiograma fetal (realizado entre 26 e 28 semanas)

- Vitalidade fetal

TRATAMENTO CLÍNICO DA GESTANTE COM DM TIPO 1

DIETA

O tratamento clínico baseou-se na adoção de medidas dietéticas apropriadas para a gestante diabética. Com a participação de nutricionista, sugeria-se a ingesta de 1.800 a 2.200 calorias diárias totais, constituídas por aproximadamente $50 \%$ de carboidratos, $30 \%$ a $35 \%$ de lipídios e $15 \%$ a $20 \%$ de proteínas. A dieta deveria ser fracionada em seis refeições, a saber: café da manhã, lanche da manhã, almoço, lanche da tarde, jantar e ceia. Os adoçantes artificiais poderiam ser ingeridos durante a gestação, com moderação, preferindo-se o uso do aspartame ou de adoçantes naturais.

\section{EXERCÍCIOS FÍSICOS}

Atividades físicas eram estimuladas quando a condição clínica da paciente permitia. Vale ressaltar que a paciente avaliava sua glicemia capilar antes de iniciar atividades físicas. Quando a glicemia era inferior a $100 \mathrm{mg} / \mathrm{dl}$, a paciente deveria realizar um lanche antes de iniciar a atividade e caso a glicemia capilar fosse superior a $200 \mathrm{mg} / \mathrm{dl}$, a atividade física era suspensa pelo risco aumentado de cetoacidose nessas situações.

\section{MONITORAÇÃO GLICÊMICA}

Ponto crucial do estudo, a monitorização glicêmica era realizada por automonitoramento da glicemia sanguínea capilar (dextro) diária, em sete períodos específicos, a saber: jejum, pós-café, pré e pós-almoço, pré e pósjantar e às 3 horas da manhã. A mensuração da glicemia pós-prandial era feita uma hora após o início da refeição. Os alvos glicêmicos de cada período 
estão detalhados na Tabela 04. As pacientes eram orientadas quanto aos valores dos alvos glicêmicos em cada momento.

Tabela 4 - Valores de normalidade do perfil glicêmico

\begin{tabular}{lll}
\hline Horário da coleta & Limite inferior & Limite superior \\
\hline Jejum & $70 \mathrm{mg} / \mathrm{dl}$ & $95 \mathrm{mg} / \mathrm{dl}$ \\
Pós-café, almoço e pós-jantar & $70 \mathrm{mg} / \mathrm{dl}$ & $140 \mathrm{mg} / \mathrm{dl}$ \\
Pré-prandiais e madrugada & $70 \mathrm{mg} / \mathrm{dl}$ & $100 \mathrm{mg} / \mathrm{dl}$ \\
\hline
\end{tabular}

FONTE: American Diabetes Association (ADA $)^{9}$

As pacientes eram orientadas a como agir em caso de hipoglicemias e quando procurar o pronto atendimento em caso de descontrole glicêmico importante. Foram ainda instruídas a anotar os valores do controle glicêmico em uma tabela prédefinida pela equipe clínica. Para maior confiabilidade dos valores trazidos, era realizada checagem dos valores da tabela com os valores das glicemias encontrados na memória do glicosímetro.

\section{INSULINOTERAPIA}

O esquema de tratamento proposto para as gestantes com diabetes baseou-se em múltiplas doses diárias de insulina (MDDI), valendo-se dos distintos tempos de ação dos diversos tipos de insulina (ação ultralenta, lenta, rápida e ultrarrápida) e organizando sua administração em doses e horários diferentes.

Para as pacientes em uso de insulina ultralenta ou para aquelas que utilizavam menos que três doses de NPH ao dia, optou-se pela modificação para esquema com três doses de NPH (café, almoço e 22 horas) associadas a doses de insulina ultrarrápida nas principais refeições (café, almoço e jantar). Os ajustes de dose de insulina eram realizados considerando-se os valores de glicemia capilar de perfil glicêmico de uma semana.

BOMBA DE INFUSÃO CONTÍNUA DE INSULINA 
Algumas pacientes, apesar de utilizarem doses fracionadas de insulina, não atingiam controle glicêmico adequado e exibiam padrão errático com vários episódios de hiper e hipoglicemia. Nesses casos, após verificar que não havia erro alimentar, optava-se pela utilização de sistema de infusão contínua de insulina (SICI). Pacientes que apresentavam nefropatia grave também se beneficiaram dessa modalidade de dispensação de insulina.

\section{MOMENTO E TIPO DE PARTO}

A via de parto nas gestantes diabéticas era sempre de indicação obstétrica. Vale ressaltar que, em fetos macrossômicos, exceto em pacientes com antecedente obstétrico de parto com RN com peso acima de $4.000 \mathrm{~g}$, priorizava-se a via alta. O momento ideal para a resolução da gestação obedece às condições abordadas a seguir:

Frente a bom controle glicêmico, objetivava-se alcançar a 40a semana. Em outras situações, as condutas baseavam-se na tabela 5 .

Tabela 5 - Situações particulares e momento de indicação de resolução da gestação

\begin{tabular}{|c|c|}
\hline SITUAÇÕES PARTICULARES & MOMENTO DO PARTO \\
\hline $\begin{array}{l}\text { Restrição de crescimento fetal } \\
\text { e/ou formas graves das } \\
\text { síndromes hipertensivas }\end{array}$ & 37 semanas \\
\hline $\begin{array}{l}\text { Macrossomia (peso fetal maior ou } \\
\text { igual a } 4.000 \mathrm{~g} \text { ) }\end{array}$ & $\begin{array}{l}\text { No diagnóstico ultrassonográfico } \\
\text { independentemente da idade gestacional }\end{array}$ \\
\hline $\begin{array}{l}\text { Feto grande para idade } \\
\text { gestacional }\end{array}$ & $\begin{array}{l}\text { SEM contraindicação para indução } \rightarrow 38 \\
\text { semanas } \\
\text { COM contraindicação para indução } \rightarrow 39 \\
\text { a } 40 \text { semanas }\end{array}$ \\
\hline $\begin{array}{l}\text { Índice de líquido amniótico } \\
\text { reduzido }\end{array}$ & $\begin{array}{l}\text { Internação e controle diário com perfil } \\
\text { biofísico fetal até diagnóstico de } \\
\text { oligoidrâmnio ou idade gestacional de } 39 \text { a } \\
40 \text { semanas. }\end{array}$ \\
\hline $\begin{array}{l}\text { Piora de controle glicêmico } \\
\text { (>30\% valores alterados) após } \\
37 \text { semanas }\end{array}$ & $\begin{array}{l}\text { Internação para otimização de tratamento } \\
\text { e controle glicêmico até 39-40 semanas }\end{array}$ \\
\hline $\begin{array}{l}\text { Impossibilidade de controle } \\
\text { glicêmico adequado, apesar da } \\
\text { otimização do tratamento }\end{array}$ & 37 semanas \\
\hline $\begin{array}{lll}\text { Nefropatia } & \text { ou } & \text { retinopatia } \\
\text { progressiva } & & \\
\end{array}$ & 37 semanas \\
\hline
\end{tabular}




\subsubsection{Análise estatística}

\subsubsection{Formação dos grupos}

O desfecho primário avaliado pelo estudo foi a categorização do peso de nascimento do recém-nascido como pequeno para idade gestacional (PIG), adequado para idade gestacional (AIG) e grande para idade gestacional (GIG). Tal classificação baseou-se no percentil de nascimento pela curva de Fenton $^{41}$ para a idade gestacional do nascimento e sexo do recém-nascido.

Os casos foram divididos em três grupos, de acordo com a classificação de peso ao nascimento para a idade gestacional e sexo, categorizando-os como (Grupo 1 - PIG, Grupo 2 - AIG, Grupo 3 - GIG) e comparados às diversas variáveis clínicas e laboratoriais.

\subsubsection{Variáveis analisadas}

Foram analisadas as associações entre as seguintes variáveis e classificação do peso do RN:

Variáveis clínicas:

- Idade (anos)

- Índice de Massa corpóreo pré-gravídico $\left(\mathrm{Kg} / \mathrm{m}^{2}\right)$

- Intervalo de tempo entre o diagnóstico de DM1 e a primeira consulta de pré-natal

- Presença ou ausência de Hipertensão arterial crônica

- Presença ou ausência de Pré-eclâmpsia

- Presença ou ausência de Nefropatia

- Presença ou ausência de Microalbuminúria

- Presença ou ausência de Retinopatia

- Idade gestacional no parto

- Peso do recém-nascido 
Microalbuminúria foi definida como a presença de valores desse marcador entre 30 e $300 \mathrm{mg} / \mathrm{vol}$ em urina de $24 \mathrm{hs}$. Retinopatia foi definida como presença de alteração relacionada ao diabetes em exame de fundo de olho realizado por oftalmologista capacitado. Nefropatia foi definida como, no primeiro trimestre, a presença de proteinúria de $24 \mathrm{hs}$ acima de $300 \mathrm{mg} / \mathrm{vol}$ ou creatinina acima de $1,2 \mathrm{mg} / \mathrm{dL}$. Hipertensão arterial crônica e pré-eclâmpsia foram definidas baseadas no consenso da International Society for the Study of Hypertension in Pregnancy (ISSHP). ${ }^{42}$

Em relação aos exames laboratoriais, coletados em cada trimestre, foram analisados:

- Idade gestacional de coleta dos exames

- Ácido úrico $(\mathrm{mg} / \mathrm{dL})$

- Creatinina $(\mathrm{mg} / \mathrm{dL})$

- Proteinúria de $24 \mathrm{hs}(\mathrm{g} / \mathrm{vol})$

- Hemoglobina glicada (\%)

- Frutosamina ( $\mu \mathrm{mol} / \mathrm{L})$

A análise do colesterol total e suas frações [colesterol total, HDL (High Density Lipoproteins), LDL(Low Density Lipoproteins) e triglicérides] foi feita somente no primeiro trimestre.

O controle glicêmico, baseado nos valores obtidos por meio de auto monitoramento de glicemia capilar, foi estudado de acordo com os trimestres da gestação. Foram analisados os seguintes parâmetros:

- Média glicêmica

- Porcentagem de Hipoglicemia

- Porcentagem de Hipoglicemia grave

- Porcentagem de Hiperglicemia

- Porcentagem de Hiperglicemia grave 
Classificou-se como hipoglicemia a glicemia capilar menor ou igual a $70 \mathrm{mg} / \mathrm{dL}$ e, como hipoglicemia grave, a glicemia capilar menor ou igual a 40 $\mathrm{mg} / \mathrm{dL}$.

Classificou-se como hiperglicemia a glicemia capilar maior que o valor de referência adotado pela Clínica Obstétrica HC-FMUSP (tabela 4) e como hiperglicemia grave, a glicemia capilar maior que $200 \mathrm{mg} / \mathrm{dL}$.

As variáveis supracitadas foram analisadas na forma da porcentagem de cada alteração, dentro do total de aferições do controle glicêmico de cada paciente em cada trimestre.

\subsubsection{Análise estatística}

Para a análise estatística foram usados os programas Excel versão 2007 para a construção do banco de dados e SPSS versão 20.0 para os cálculos estatísticos.

Os dados qualitativos foram descritos utilizando-se medidas de frequência absoluta e relativa.

Os dados quantitativos foram apresentados em forma de medidas de posição e de dispersão (média, desvio-padrão, mínimo e máximo).

Para a avaliação de associação entre as variáveis qualitativas foi utilizado teste qui-quadrado ou teste exato de Fisher, quando adequado. Devido às características da amostra, foi utilizado o Teste de amostras independentes de Kruskal-Wallis para comparação dos grupos em relação a variáveis quantitativas e, quando significativo, análise por pares.

Para avaliar as variáveis preditoras do desfecho final, optou-se por modelo de regressão multinomial e foi utilizado método de Stepwise para seleção das variáveis finais do modelo. ${ }^{43}$

Foi adotado nível de significância de 0,05 para a interpretação dos resultados. 


\section{Resultados}




\section{Resultados}

Durante a realização do estudo, 77 pacientes iniciaram o pré-natal no primeiro trimestre na Clínica Obstétrica do HC-FMUSP. Foram excluídas do estudo 17 pacientes: quatro foram encaminhadas como DM1, mas apresentavam dosagem normal ou aumentada de peptídeo $\mathrm{C}$, três apresentaram malformações fetais, sete evoluíram com abortamento e outras três perderam o seguimento. Assim, a amostra final do estudo foi constituída de 60 pacientes.

Fluxograma 1. Fluxograma de pacientes do estudo.

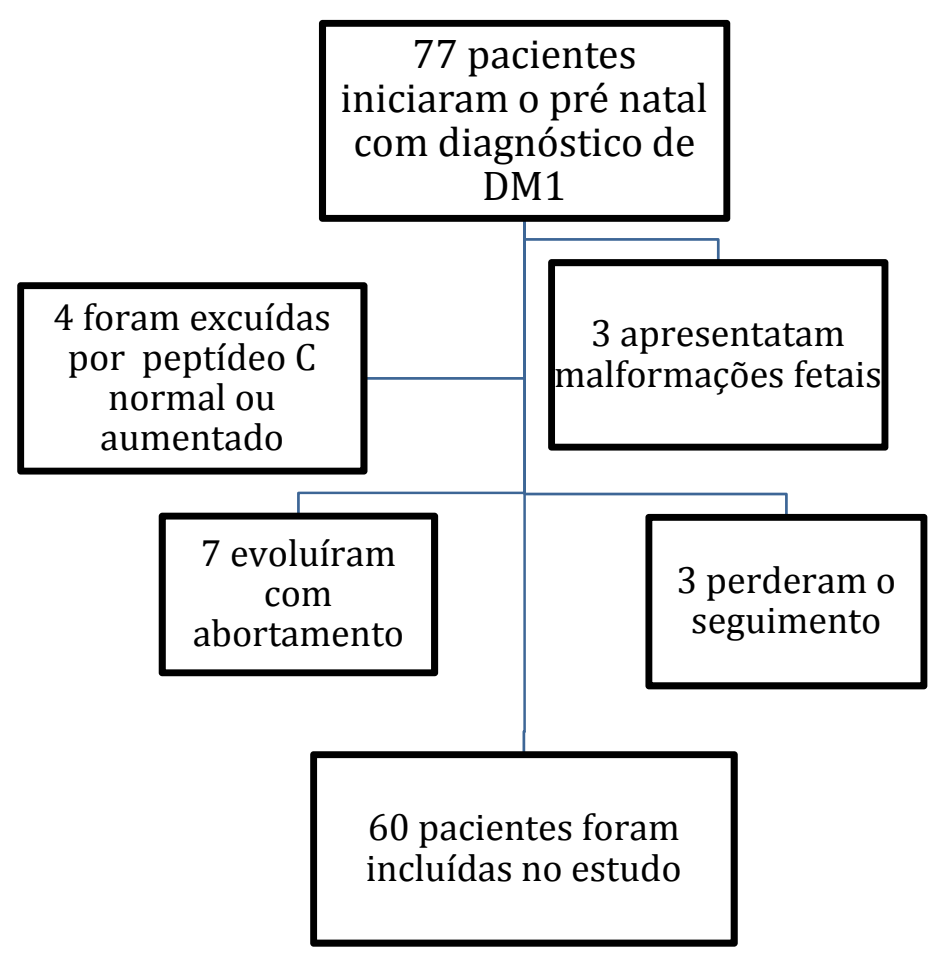

Os casos foram divididos em três grupos, de acordo com a classificação do recém-nascido, segundo peso e sexo, conforme a idade gestacional no nascimento. ${ }^{41} \mathrm{~A}$ tabela 6 demonstra a distribuição das pacientes nos três grupos. 
Tabela 6 - Distribuição das pacientes com diabetes mellitus tipo 1, nos três grupos de estudo, segundo a classificação do recémnascido pela curva de Fenton et al. ${ }^{41}$ - HC-FMUSP - 2013 a 2016

\begin{tabular}{lcc}
\hline Grupo & $\mathbf{n}$ & Frequência (\%) \\
\hline PIG* $^{*}$ & 6 & 10 \\
AIG $^{\#}$ & 35 & 58,3 \\
GIG $^{\$}$ & 19 & 31,7 \\
\hline PIG - Pequeno para a idade gestacional \\
AIG - Adequado para a idade gestacional \\
GIG - Grande para a idade gestacional
\end{tabular}

Do total de pacientes avaliadas, 34/60(56,7\%) utilizaram SICI sendo que estavam distribuídas nos três grupos da seguinte maneira: 6/6 (100\%) no grupo PIG, $21 / 35$ (60\%) no grupo AIG e 7/19 (36,9\%) no grupo GIG (QuiQuadrado de Pearson; $p=0,02$ ).

\subsection{Características das gestantes no início do pré-natal}

A tabela 7 demonstra as características das gestantes de cada grupo no início do pré-natal. Somente a idade das participantes foi significativamente diferente. A média de idade materna mais elevada foi observada no grupo PIG. Não houve diferença entre os grupos em relação ao IMC materno pré-concepcional e o tempo transcorrido desde o diagnóstico do DM1 até o início do pré-natal. 
Tabela 7 - Características das gestantes com diabetes mellitus tipo 1, no início do pré-natal, nos diferentes grupos HC-FMUSP 2013 a 2016

\begin{tabular}{|c|c|c|c|c|c|c|}
\hline & Grupos & Média & DP & Min & $\operatorname{Max}$ & $\mathbf{p}^{\#}$ \\
\hline \multirow{3}{*}{$\begin{array}{l}\text { Idade } \\
\text { (anos) }\end{array}$} & PIG & 30,5 & 9,67 & 17 & 45 & \multirow[t]{3}{*}{$\overline{0,048}$} \\
\hline & AIG & 29,37 & 5,72 & 19 & 39 & \\
\hline & GIG & 24,74 & 5,80 & 16 & 34 & \\
\hline \multirow{3}{*}{$\begin{array}{l}\text { IMC pré- } \\
\text { gravídico } \\
\left(\mathrm{Kg} / \mathrm{m}^{2}\right)\end{array}$} & PIG & 21,67 & 2,33 & 19 & 25 & \multirow[t]{3}{*}{0,280} \\
\hline & AIG & 23,60 & 3,03 & 19 & 35 & \\
\hline & GIG & 23,53 & 4,7 & 16 & 35 & \\
\hline \multirow{3}{*}{$\begin{array}{l}\text { Tempo de } \\
\text { doença } \\
\text { (anos) }\end{array}$} & PIG & 15,33 & 4,08 & 10 & 20 & \multirow[t]{3}{*}{0,608} \\
\hline & AIG & 16,17 & 7,88 & 3 & 30 & \\
\hline & GIG & 13,79 & 6,16 & 4 & 28 & \\
\hline
\end{tabular}

DP - Desvio Padrão, Min - Mínimo, Max - Máximo, PIG - Pequeno para a idade gestacional, AIG - Adequado para a idade gestacional, GIG - Grande para a idade gestacional

\# - Teste de amostras independentes de Kruskal-Wallis

\subsection{Intercorrências clínicas e obstétricas}

A frequência de hipertensão arterial crônica foi de 15/60 (25\%) dos casos e associou-se, de forma estatisticamente significativa, à classificação de peso ao nascimento, observando-se maior frequência dessa doença quanto menor o peso no nascimento $(p=0,008)$, Tabela 8 .

A pré-eclâmpsia foi observada em 17/60(28,3\%) dos casos e se associou de maneira significativa com a classificação do peso no nascimento. Observa-se que, no grupo PIG, esse evento esteve presente em 2/6 (33,3\%) dos $\operatorname{casos}(p=0,023)$, Tabela 8 .

A nefropatia diabética foi identificada em 19/60 (31,7\%)casos e associou-se de forma estatisticamente significativa, à classificação de peso ao nascimento $(p=0,001)$. Sua frequência foi de $6 / 6(100 \%)$ no grupo PIG e de 4/19 $(21,1 \%)$ no grupo GIG, Tabela 8. 
A frequência de retinopatia diabética foi de 25\%. Entretanto, essa variável não se associou, de maneira significativa, com a classificação do peso no nascimento ( $p=0,238)$.

Tabela 8 - Distribuição dos casos de hipertensão arterial crônica, préeclâmpsia, nefropatia, microalbuminúria e retinopatia nos diferentes grupos em gestantes com diabetes mellitus tipo 1 - HC-FMUSP - 2013 a 2016

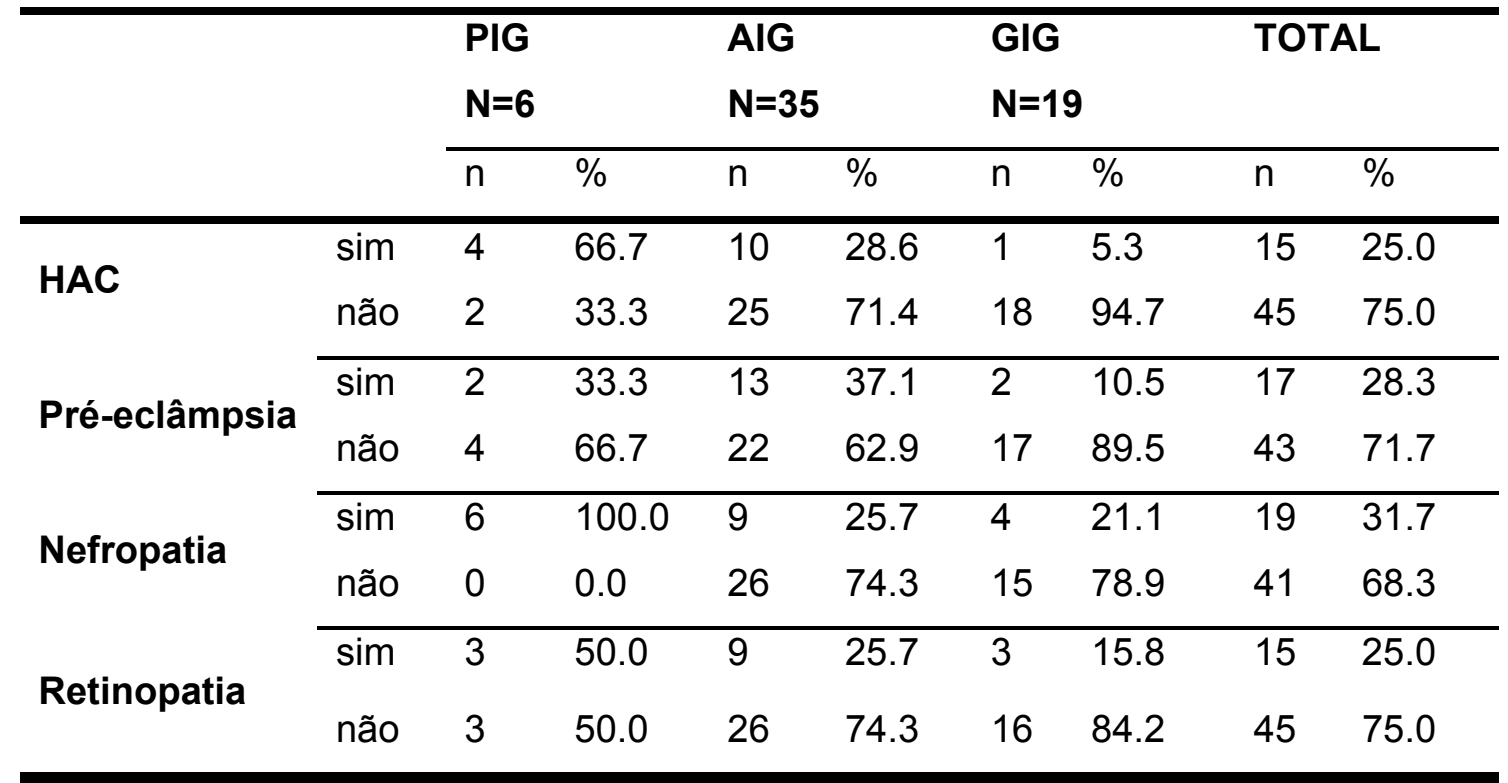

PIG - Pequeno para a idade gestacional, AIG - Adequado para a idade gestacional, GIG - Grande para a idade gestacional

\# - Teste de amostras independentes de Kruskal-Wallis

\subsection{Dados do parto}

A frequência de partos prematuros foi de $26,7 \%$. A tabela 9 descreve a idade gestacional dos partos, que foi semelhante nos três grupos. 
Tabela 9 -Idade gestacional e peso do recém-nascido no parto em gestantes com diabetes mellitus do tipo 1 nos grupos estudados - HC-FMUSP - 2013 a 2016

\begin{tabular}{lllllll}
\hline & Grupos & Média & DP & Min & Max & $\mathbf{p}^{\#}$ \\
\hline Idade gestacional no & PIG & 36,23 & 1,15 & 34,57 & 37,50 & \\
parto (semanas) & AIG & 37,07 & 1,09 & 34,10 & 39,14 &, 332 \\
& GIG & 36,87 & 1,16 & 33,71 & 39,00 & \\
\cline { 2 - 7 } Peso ao Nascimento (g) & PIG & 1976 & 376 & 1520 & 2385 & \\
& AIG & 3085 & 317 & 2240 & 3630 &, 001 \\
& GIG & 3754 & 390 & 3105 & 4500 & \\
\hline
\end{tabular}

DP - Desvio Padrão, Min - Mínimo, Max - Máximo, PIG - Pequeno para a idade gestacional, AIG - Adequado para a idade gestacional, GIG - Grande para a idade gestacional

\# - Teste de amostras independentes de Kruskal-Wallis

A cesárea foi a via de parto mais frequente nessas pacientes. $\mathrm{O}$ crescimento fetal não se associou ao modo do parto $(p=0,333)$. A tabela 10 demonstra tais achados.

Tabela 10 - Via de parto em gestantes com diabetes mellitus do tipo 1 nos grupos estudados - HC-FMUSP - 2013 a 2016

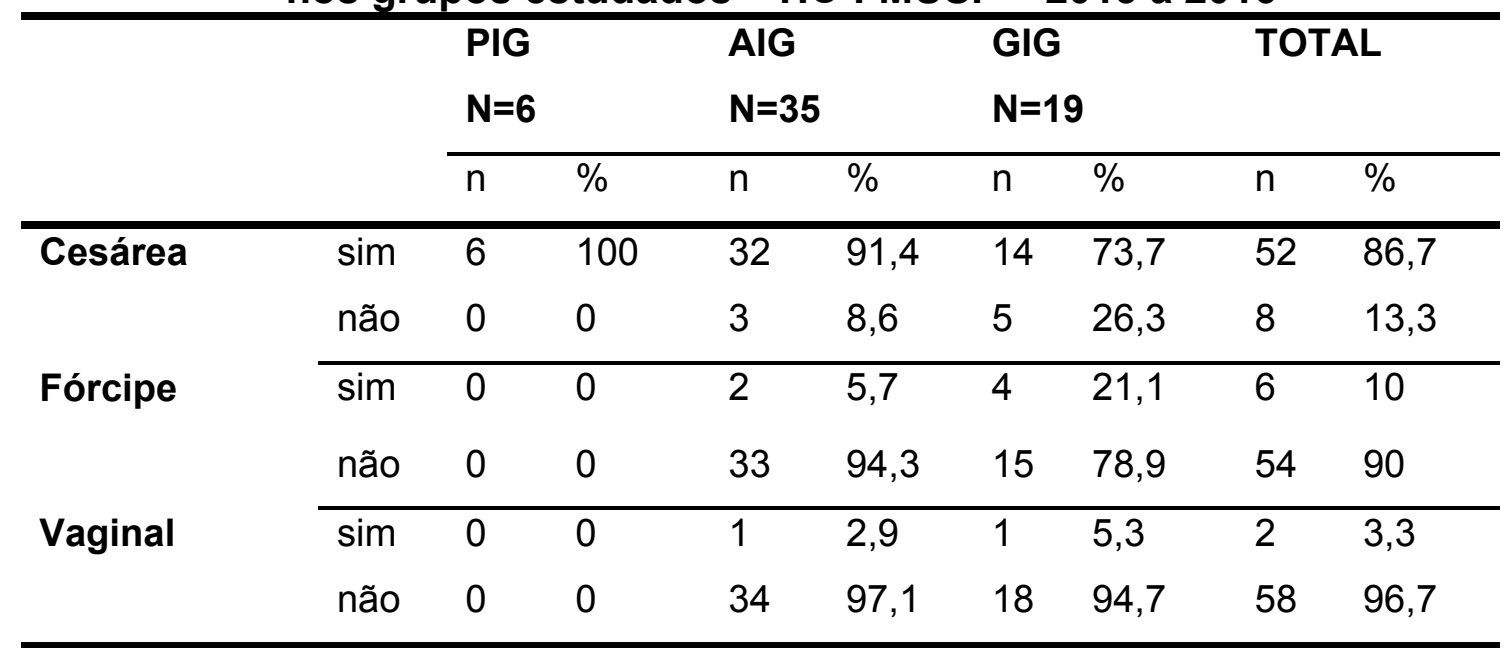

PIG - Pequeno para a idade gestacional, AIG - Adequado para a idade gestacional, GIG - Grande para a idade gestacional 


\subsection{Marcadores laboratoriais e relação com classificação do peso no nascimento}

\subsubsection{Tempo de coleta dos exames}

Os exames laboratoriais foram colhidos durante o pré-natal. A tabela 11 mostra a idade gestacional em que foram realizadas as coletas dos exames e demonstra semelhança entre os grupos.

Tabela 11 - Idade gestacional da coleta de exames das gestantes com diabetes mellitus tipo 1 - HC-FMUSP - 2013 a 2016

\begin{tabular}{lllllll}
\hline & Grupos & Média & DP & Min & Max & $\mathbf{p}^{\#}$ \\
\hline Primeiro & PIG & 8,83 & 2,46 & 6 & 12 & 0,926 \\
Trimestre & AIG & 9,20 & 2,37 & 5 & 13,86 & \\
& GIG & 9,19 & 2,15 & 5,29 & 13,86 & \\
\hline Segundo & PIG & 25,03 & 3,07 & 19,14 & 27,8 & 0,199 \\
trimestre & AIG & 22,41 & 3,32 & 17 & 27,8 & \\
& GIG & 23,30 & 3,08 & 17,29 & 27,8 & \\
\hline Terceiro & PIG & 34,99 & 1,52 & 33,28 & 37 & 0,407 \\
trimestre & AIG & 33,53 & 2,72 & 28 & 37,43 & \\
& GIG & 33,53 & 1,92 & 30 & 36,43 &
\end{tabular}

DP - Desvio Padrão, Min - Mínimo, Max - Máximo, PIG - Pequeno para a idade gestacional, AIG - Adequado para a idade gestacional, GIG - Grande para a idade gestacional

\# - Teste de amostras independentes de Kruskal-Wallis

O colesterol total, triglicérides, HDL, LDL e TSH foram dosados apenas no primeiro trimestre e os resultados foram semelhantes entre os grupos avaliados (respectivamente: $p=0,056 ; p=0,614 ; p=0,214 ; p=0,095$; $p=0,775)$. 


\subsection{2. Ácido Úrico}

Ocorreu associação entre os valores da dosagem sérica de ácido úrico e o crescimento fetal, em todos os trimestres. Os valores de ácido úrico mais elevados associaram-se ao desfecho PIG, conforme demonstrado na tabela 12.

Tabela 12 - Variação da dosagem sérica de ácido úrico nos três grupos conforme os trimestres da gestação - HC-FMUSP - 2013 a 2016

\begin{tabular}{ccccccc}
\hline $\begin{array}{c}\text { Ácido } \\
\text { Úrico } \\
(\mathbf{m g} / \mathbf{d L})\end{array}$ & Grupos & Média & DP & Mín & Max & $\mathbf{p}^{\#}$ \\
\hline Primeiro & PIG & 5,17 & 2,16 & 2,00 & 8,40 & \\
Trimestre & AIG & 3,01 & 0,81 & 1,20 & 5,00 &, 004 \\
& GIG & 2,53 & 0,86 & 1,70 & 5,20 & \\
\hline Segundo & PIG & 6,00 & 2,76 & 2,60 & 9,90 & \\
Trimestre & AIG & 3,08 & 0,93 & 1,40 & 5,90 &, 010 \\
& GIG & 2,65 & 0,86 & 1,90 & 4,70 & \\
\hline Terceiro & PIG & 7,02 & 2,04 & 3,70 & 9,70 & \\
Trimestre & AIG & 3,99 & 1,41 & 1,60 & 7,20 &, 004 \\
& GIG & 3,57 & 1,31 & 2,10 & 6,50 & \\
\hline
\end{tabular}

DP - Desvio Padrão, Min - Mínimo, Max - Máximo, PIG - Pequeno para a idade gestacional, AIG - Adequado para a idade gestacional, GIG - Grande para a idade gestacional

\# - Teste de amostras independentes de Kruskal-Wallis

Ao realizar comparações aos pares, no primeiro e no segundo trimestres, houve diferença entre os grupos PIG e GIG, $p=0,004$ e $p=0,008$, respectivamente. No terceiro trimestre, houve diferença entre os grupos PIG e GIG $(p=0,003)$ e PIG e AIG $(p=0,009)$.

\subsubsection{Creatinina}

Ocorreu associação entre a classificação de peso ao nascimento e a dosagem de creatinina sérica em todos os trimestres. Os valores de creatinina mais elevados associaram-se ao desfecho PIG, conforme demonstrado na tabela 13. 
Tabela 13 - Variação da dosagem sérica de creatinina nos grupos estudados conforme os trimestres da gestação - HC-FMUSP -2013 a 2016

\begin{tabular}{ccccccc}
\hline $\begin{array}{c}\text { Creatinina } \\
(\mathbf{m g} / \mathbf{d L})\end{array}$ & Grupos & Média & DP & Mín & Max & $\mathbf{p}^{\#}$ \\
\hline \multirow{3}{*}{ Primeiro Trimestre } & PIG & 1,48 & 0,63 & 0,59 & 2,12 & \\
& AIG & 0,65 & 0,19 & 0,37 & 1,38 &, 003 \\
& GIG & 0,59 & 0,12 & 0,45 & 0,94 & \\
\hline \multirow{3}{*}{ Segundo Trimestre } & PIG & 1,54 & 0,82 & 0,53 & 2,39 & \\
& AIG & 0,59 & 0,18 & 0,34 & 1,22 &, 009 \\
& GIG & 0,58 & 0,11 & 0,37 & 0,73 & \\
\hline \multirow{3}{*}{ Terceiro Trimestre } & PIG & 2,23 & 1,20 & 0,56 & 3,74 & \\
& AIG & 0,67 & 0,21 & 0,34 & 1,36 &, 001 \\
& GIG & 0,51 & 0,11 & 0,25 & 0,67 & \\
\hline
\end{tabular}

DP - Desvio Padrão, Min - Mínimo, Max - Máximo, PIG - Pequeno para a idade gestacional, AIG - Adequado para a idade gestacional, GIG - Grande para a idade gestacional

\# - Teste de amostras independentes de Kruskal-Wallis

Ao realizar comparações aos pares, no primeiro trimestre, houve diferença entre os grupos PIG e GIG $(p=0,002)$ e PIG e AIG $(p=0,013)$. No segundo trimestre, houve diferença entre os grupos PIG e GIG $(p=0,006)$ e PIG e AIG $(p=0,044)$. No terceiro trimestre, houve diferença entre os grupos PIG e GIG $(p=0,001)$ e PIG e AIG $(p=0,047)$ e AIG e GIG $(p=0,011)$.

\subsubsection{Proteinúria de 24 horas}

Houve associação entre os valores de proteinúria de 24 horas e o peso ao nascimento em todos os trimestres. Os valores de proteinúria de 24 horas mais elevados associaram-se ao desfecho PIG, conforme demonstrado na tabela 14. 
Tabela 14 - Variação da dosagem de proteinúria de 24 horas de acordo com a classificação de peso do recém-nascido conforme os trimestres da gestação - HC-FMUSP - 2013 a 2016

\begin{tabular}{lllllll}
\hline $\begin{array}{c}\text { Proteinúria de } \\
\text { 24 horas } \\
\text { (mg/dL) }\end{array}$ & Grupos & Média & DP & Mín & Max & $\mathbf{p}^{\#}$ \\
\hline \multirow{2}{*}{ Primeiro Trimestre } & PIG & 1,99 & 1,88 & 0,30 & 4,82 & \\
& AIG & 0,21 & 0,19 & 0,06 & 0,82 &, 001 \\
& GIG & 0,20 & 0,17 & 0,07 & 0,66 & \\
\hline \multirow{3}{*}{ Segundo Trimestre } & PIG & 2,88 & 2,47 & 0,25 & 6,12 & \\
& AIG & 0,39 & 0,55 & 0,00 & 2,67 &, 005 \\
& GIG & 0,20 & 0,11 & 0,04 & 0,37 & \\
\hline \multirow{3}{*}{ Terceiro Trimestre } & PIG & 4,91 & 5,77 & 0,13 & 15,84 & \\
& AIG & 0,73 & 1,47 & 0,07 & 7,53 &, 010 \\
& GIG & 0,29 & 0,37 & 0,05 & 1,46 & \\
\hline
\end{tabular}

DP - Desvio Padrão, Min - Mínimo, Max - Máximo, PIG - Pequeno para a idade gestacional, AIG - Adequado para a idade gestacional, GIG - Grande para a idade gestacional

\# - Teste de amostras independentes de Kruskal-Wallis

Ao realizar comparações aos pares, no primeiro trimestre, houve diferença entre os grupos PIG e GIG (p=0,002) e PIG e AIG $(p=0,002)$. No segundo trimestre, houve diferença entre os grupos PIG e GIG ( $p=0,010)$ e PIG e AIG $(p=0,006)$. No terceiro trimestre, houve diferença entre os grupos PIG e GIG ( $p=0,007)$. 


\subsection{Controle Glicêmico}

\subsubsection{Hemoglobina Glicada}

Não houve diferença significativa entre os grupos, quanto aos valores de $\mathrm{HbA1c}$, nos diferentes trimestres da gestação, conforme descrito na tabela 15.

Tabela 15 -Valores de hemoglobina glicada conforme os trimestres da gestação nos diferentes grupos - HC-FMUSP - 2013 a 2016

\begin{tabular}{llccccc}
\hline HbA1c (\%) & Grupos & Média & DP & Mín & Max & $\mathbf{p}^{\#}$ \\
\hline \multirow{3}{*}{ Primeiro Trimestre } & PIG & 8,23 & 1,43 & 6,30 & 9,90 & \\
& AIG & 8,11 & 1,74 & 5,70 & 11,80 & \multirow{2}{*}{, 576} \\
& GIG & 8,63 & 1,60 & 6,30 & 12,50 & \\
\hline \multirow{3}{*}{ Segundo Trimestre } & PIG & 6,37 & 1,16 & 5,30 & 7,90 & \\
& AIG & 6,20 & 0,82 & 4,50 & 8,00 & \multirow{2}{*}{, 503} \\
& GIG & 6,42 & 0,56 & 5,40 & 7,40 & \\
\hline \multirow{3}{*}{ Terceiro Trimestre } & PIG & 5,93 & 1,77 & 4,60 & 9,40 & \\
& AIG & 6,29 & 0,89 & 5,10 & 9,00 & \multirow{2}{*}{, 102} \\
& GIG & 6,36 & 0,61 & 5,30 & 7,80 & \\
\hline
\end{tabular}

DP - Desvio Padrão, Min - Mínimo, Max - Máximo, PIG - Pequeno para a idade gestacional, AIG - Adequado para a idade gestacional, GIG - Grande para a idade gestacional

\# - Teste de amostras independentes de Kruskal-Wallis

\subsubsection{Frutosamina}

Não houve diferença significativa entre os grupos, quanto aos valores de frutosamina, nos diferentes trimestres da gestação, conforme descrito na tabela 16. 
Tabela 16 -Valores de frutosamina nos trimestres da gestação nos três grupos avaliados - HC-FMUSP - 2013 a 2016.

\begin{tabular}{ccccccc}
\hline $\begin{array}{c}\text { Frutosamina } \\
(\boldsymbol{\mu} \mathbf{m o l} / \mathbf{L})\end{array}$ & Grupos & Média & DP & Mín & Max & $\mathbf{p}^{\#}$ \\
\hline \multirow{3}{*}{ Primeiro Trimestre } & PIG & 312,17 & 68 & 244 & 432 & \\
& AIG & 334,74 & 78 & 224 & 531 &, 336 \\
& GIG & 358,35 & 70 & 274 & 487 & \\
\hline \multirow{3}{*}{ Segundo Trimestre } & PIG & 243,50 & 58 & 165 & 344 & \\
& AIG & 245,88 & 32 & 187 & 335 &, 106 \\
& GIG & 266,53 & 34 & 213 & 331 & \\
\hline \multirow{3}{*}{ Terceiro Trimestre } & PIG & 201,50 & 52 & 143 & 276 & \\
& AIG & 224,94 & 31 & 139 & 283 &, 515 \\
& GIG & 220,81 & 29 & 173 & 270 & \\
\hline
\end{tabular}

DP - Desvio Padrão, Min - Mínimo, Max - Máximo, PIG - Pequeno para a idade gestacional, AIG - Adequado para a idade gestacional, GIG - Grande para a idade gestacional

\# - Teste de amostras independentes de Kruskal-Wallis

\subsubsection{Média glicêmica}

A média glicêmica do terceiro trimestre foi a única a se correlacionar com o desfecho estudado. A associação nos demais momentos da gravidez não se mostrou significativa conforme descrito na tabela 17 .

Tabela 17 - Média glicêmica nos trimestres da gestação nos grupos estudados - HC-FMUSP - 2013 a 2016

\begin{tabular}{|c|c|c|c|c|c|c|}
\hline $\begin{array}{c}\text { Média glicêmica } \\
(\mathrm{mg} / \mathrm{dL})\end{array}$ & Grupos & Média & DP & Mín & Max & $\mathbf{p}^{\#}$ \\
\hline \multirow{3}{*}{ Primeiro Trimestre } & PIG & 118 & 16 & 98 & 142 & \multirow{3}{*}{,335 } \\
\hline & AIG & 132 & 23 & 94 & 204 & \\
\hline & GIG & 128 & 12 & 107 & 147 & \\
\hline \multirow{3}{*}{ Segundo Trimestre } & PIG & 112 & 11 & 99 & 131 & \multirow{3}{*}{,091 } \\
\hline & AIG & 119 & 15 & 92 & 147 & \\
\hline & GIG & 126 & 17 & 99 & 159 & \\
\hline \multirow{3}{*}{ Terceiro Trimestre } & PIG & 105 & 14 & 85 & 121 & \multirow{3}{*}{,006 } \\
\hline & AIG & 114 & 12 & 94 & 147 & \\
\hline & GIG & 124 & 14 & 101 & 162 & \\
\hline $\begin{array}{l}\text { DP - Desvio Padrão } \\
\text { idade gestacional, A } \\
\text { para a idade gestacic } \\
\# \text { - Teste de amostras }\end{array}$ & $\begin{array}{l}\text { in - N } \\
\text { - Ade } \\
\text { depen }\end{array}$ & $\begin{array}{l}\operatorname{Max} \\
\operatorname{ara} a\end{array}$ & xim & DIG - & eque & \\
\hline
\end{tabular}


Ao realizar comparações aos pares, no terceiro trimestre, houve diferença entre os grupos PIG e GIG ( $p=0,017)$ e AIG e GIG ( $p=0,034)$.

\subsubsection{Porcentagem de Hipoglicemia}

A porcentagem de valores do controle glicêmico demonstrando hipoglicemia menor ou igual a $70 \mathrm{mg} / \mathrm{dL}$ associou-se ao desfecho estudado somente no terceiro trimestre. O grupo GIG apresentou menor frequência de hipoglicemias no terceiro trimestre quando comparado aos demais grupos. A associação nos demais momentos da gravidez não se mostrou significativa, conforme descrito na tabela 18.

Tabela 18 - Porcentagem de hipoglicemias nos trimestres da gestação nos diferentes grupos - HC-FMUSP - 2013 a 2016

\begin{tabular}{|c|c|c|c|c|c|c|}
\hline $\begin{array}{c}\text { Porcentagem de } \\
\text { hipoglicemias } \\
(\%)\end{array}$ & Grupos & Média & DP & Mín & Max & $\mathbf{p}^{\#}$ \\
\hline \multirow{3}{*}{ Primeiro Trimestre } & PIG & 16,66 & 6,48 & 8,98 & 27,08 & \multirow{3}{*}{,582 } \\
\hline & AIG & 13,72 & 5,83 & 4,25 & 25,09 & \\
\hline & GIG & 14,31 & 7,64 & 0,59 & 25,16 & \\
\hline \multirow{3}{*}{ Segundo Trimestre } & PIG & 12,13 & 3,82 & 8,74 & 18,49 & \multirow{3}{*}{,443 } \\
\hline & AIG & 13,26 & 4,62 & 2,68 & 24,3 & \\
\hline & GIG & 11,11 & 6,10 & 1,6 & 23,9 & \\
\hline \multirow{3}{*}{ Terceiro Trimestre } & PIG & 16,30 & 7,19 & 2,24 & 23,18 & \multirow{3}{*}{,027 } \\
\hline & AIG & 11,31 & 4,73 & 3,38 & 24,39 & \\
\hline & GIG & 9,00 & 5,15 & 0,95 & 18,31 & \\
\hline \multicolumn{7}{|c|}{$\begin{array}{l}\text { DP - Desvio Padrão, Min - Mínimo, Max - Máximo, PIG - Pequeno para a } \\
\text { idade gestacional, AIG - Adequado para a idade gestacional, GIG - Grande } \\
\text { para a idade gestacional } \\
\# \text { - Teste de amostras independentes de Kruskal-Wallis }\end{array}$} \\
\hline
\end{tabular}




\subsubsection{Porcentagem de Hipoglicemia grave}

A porcentagem de valores do controle glicêmico demonstrando hipoglicemia menor ou igual a $40 \mathrm{mg} / \mathrm{dL}$ não se correlacionou ao desfecho estudado em nenhum trimestre, conforme descrito na tabela 19.

Tabela 19 - Porcentagem de hipoglicemias graves nos trimestres da gestação nos três grupos estudados - HC-FMUSP - 2013 a 2016

\begin{tabular}{llccccc}
\hline $\begin{array}{c}\text { Porcentagem de } \\
\text { hipoglicemias } \\
\text { graves (\%) }\end{array}$ & Grupos & Média & DP & Mín & Max & p $^{\#}$ \\
\hline \multirow{3}{*}{ Primeiro Trimestre } & PIG & 3,84 & 4,47 & 1,00 & 12,50 & \\
& AIG & 2,88 & 2,68 & 0,00 & 9,93 &, 875 \\
& GIG & 3,64 & 3,94 & 0,00 & 13,24 & \\
\hline \multirow{3}{*}{ Segundo Trimestre } & PIG & 1,27 & 1,06 & 0,46 & 3,11 & \\
& AIG & 2,04 & 1,38 & 0,00 & 4,76 &, 635 \\
& GIG & 2,47 & 2,25 & 0,00 & 5,91 & \\
\hline \multirow{2}{*}{ Terceiro Trimestre } & PIG & 2,75 & 2,77 & 0,22 & 7,65 & \\
& AIG & 1,38 & 1,18 & 0,00 & 6,26 &, 596 \\
& GIG & 1,82 & 1,91 & 0,00 & 5,93 & \\
\hline
\end{tabular}

DP - Desvio Padrão, Min - Mínimo, Max - Máximo, PIG - Pequeno para a idade gestacional, AIG - Adequado para a idade gestacional, GIG - Grande para a idade gestacional

\# - Teste de amostras independentes de Kruskal-Wallis

\subsubsection{Porcentagem de Hiperglicemia}

A porcentagem de valores do controle glicêmico demonstrando hiperglicemia (acima dos valores de referência para glicemia estabelecidos para o horário) associou-se ao desfecho estudado somente no terceiro trimestre. A associação nos demais momentos da gravidez não se mostrou significativa, conforme descrito na tabela 20. 
Tabela 20 - Porcentagem de hiperglicemias de acordo com a classificação de peso do recém-nascido conforme os trimestres da gestação - HC-FMUSP - 2013 a 2016

\begin{tabular}{llccccc}
\hline $\begin{array}{l}\text { Porcentagem de } \\
\text { Hiperglicemias } \\
(\%)\end{array}$ & Grupos & Média & DP & Mín & Max & $\mathbf{p}^{\#}$ \\
\hline \multirow{3}{*}{ Primeiro Trimestre } & PIG & 38,88 & 8,24 & 24,61 & 48,18 & \\
& AIG & 48,30 & 16,29 & 18,30 & 84,78 &, 155 \\
& GIG & 46,25 & 8,65 & 30,40 & 62,27 & \\
\hline \multirow{3}{*}{ Segundo Trimestre } & PIG & 34,23 & 10,52 & 20,57 & 51,60 & \\
& AIG & 40,06 & 14,12 & 12,18 & 67,09 &, 180 \\
& GIG & 45,31 & 14,32 & 21,21 & 69,79 & \\
\hline \multirow{3}{*}{ Terceiro Trimestre } & PIG & 27,42 & 13,24 & 6,47 & 42,08 & \\
& AIG & 35,80 & 13,06 & 12,15 & 64,45 &, 014 \\
& GIG & 45,03 & 13,46 & 24,53 & 77,89 & \\
\hline
\end{tabular}

DP - Desvio Padrão, Min - Mínimo, Max - Máximo, PIG - Pequeno para a idade gestacional, AIG - Adequado para a idade gestacional, GIG - Grande para a idade gestacional

\# - Teste de amostras independentes de Kruskal-Wallis

Ao realizar comparações aos pares, no terceiro trimestre, houve diferença entre os grupos PIG e GIG ( $p=0,030)$.

\subsubsection{Porcentagem de Hiperglicemia grave}

A porcentagem de valores do controle glicêmico demonstrando hiperglicemia maior ou igual a $200 \mathrm{mg} / \mathrm{dL}$, não se correlacionou ao desfecho estudado em nenhum trimestre. 
Tabela 21 - Porcentagem de hiperglicemias grave de acordo com a classificação de peso do recém-nascido conforme os trimestres da gestação - HC-FMUSP - 2013 a 2016

\begin{tabular}{llccccc}
\hline $\begin{array}{l}\text { Porcentagem de } \\
\text { hiperglicemias } \\
\text { graves (\%) }\end{array}$ & Grupos & Média & DP & Mín & Max & $\mathbf{p}^{\#}$ \\
\hline \multirow{2}{*}{ Primeiro Trimestre } & PIG & 8,19 & 7,04 & 1,25 & 20,00 & \\
& AIG & 13,85 & 12,69 & 0,00 & 60,86 &, 558 \\
& GIG & 10,51 & 6,56 & 0,00 & 23,18 & \\
\hline \multirow{3}{*}{ Segundo Trimestre } & PIG & 3,72 & 3,62 & 0,00 & 9,18 & \\
& AIG & 6,49 & 5,78 & 0,19 & 17,96 &, 209 \\
& GIG & 9,02 & 7,39 & 0,23 & 25,00 & \\
\hline \multirow{3}{*}{ Terceiro Trimestre } & PIG & 2,47 & 2,37 & 0,00 & 5,88 & \\
& AIG & 3,76 & 3,86 & 0,00 & 18,07 &, 078 \\
& GIG & 7,02 & 6,29 & 0,26 & 23,58 & \\
\hline
\end{tabular}

DP - Desvio Padrão, Min - Mínimo, Max - Máximo, PIG - Pequeno para a idade gestacional, AIG - Adequado para a idade gestacional, GIG - Grande para a idade gestacional

\# - Teste de amostras independentes de Kruskal-Wallis

\subsection{Análise de fatores preditores do crescimento fetal}

Ajustamos modelos de regressão multinomial para o desfecho com três categorias (PIG, GIG e AIG) com covariáveis significativas relacionadas ao controle glicêmico e marcadores laboratoriais: média glicêmica, ácido úrico, creatinina e proteinúria avaliados no primeiro e no terceiro trimestres. A categoria AIG foi considerada como de referência. ${ }^{43}$

Consideramos um modelo log-linear da forma

$\log \left(\frac{p_{k}}{p_{1}}\right)=b 0+b 1 * x 1+b 2 * x 2+b 3 * x 3+b 4 * x 4, \quad$ com $k=2,3$

em que $p_{1}$ é a probabilidade de ser AIG, $p_{2}$ é a probabilidade de ser PIG e $p_{3}$ é a probabilidade de ser GIG. Ainda, $x 1$ representa glicemia, $x 2$ representa ácido úrico, $x 3$ é creatinina e $x 4$ representa proteinúria e os b's representam os coeficientes do modelo. 


\subsubsection{Primeiro Trimestre}

$\mathrm{Na}$ tabela 22 estão os ajustes do modelo para o primeiro trimestre. Nessa análise, nenhuma covariável foi significativa para os defechos PIG ou GIG.

Tabela 22 - Ajustes do modelo preditor de alterações de crescimento fetal em gestantes com DM1 para o primeiro trimestre

\begin{tabular}{|c|c|c|c|c|}
\hline & Covariáveis & Coeficientes & $\begin{array}{c}\text { Erro } \\
\text { padrão }\end{array}$ & Valor p \\
\hline \multirow[t]{5}{*}{ PIG } & Intercept & 3.199 & 6.729 & .635 \\
\hline & MediaGlic1trim & -.066 & .057 & .247 \\
\hline & Ac.Urico1 & .079 & .924 & .932 \\
\hline & Creat1 & 1.484 & 4.554 & .745 \\
\hline & Ptu24h1 & 3.254 & 3.173 & .305 \\
\hline \multirow[t]{5}{*}{ GIG } & Intercept & 2.397 & 3.202 & .454 \\
\hline & MediaGlic1trim & -.002 & .021 & .924 \\
\hline & Ac.Urico1 & -.876 & .528 & .097 \\
\hline & Creat1 & -.754 & 2.588 & .771 \\
\hline & Ptu24h1 & .000 & 2.171 & 0.999 \\
\hline \multicolumn{5}{|c|}{$\begin{array}{l}\text { PIG - Pequeno para a idade gestacional, GIG - Grande } \\
\text { para a idade gestacional, MediaGlic1trim - Média glicêmica } \\
\text { do primeiro trimestre, Ac.Urico1 - Ácido Úrico no primeiro } \\
\text { trimestre, Creat1 - Creatinina sérica no primeiro trimestre, } \\
\text { Ptu24h1 - Proteinúria de } 24 \text { hs no primeiro trimestre. }\end{array}$} \\
\hline
\end{tabular}

\subsubsection{Segundo Trimestre}

$\mathrm{Na}$ tabela 23 estão os ajustes do modelo para o primeiro trimestre. Nessa análise, nenhuma covariável foi significativa para os defechos PIG ou GIG. 
Tabela 23 - Ajustes do modelo preditor de alterações de crescimento fetal em gestantes com DM1 para o segundo trimestre

\begin{tabular}{lllll}
\hline & Covariáveis & Coeficientes & $\begin{array}{c}\text { Erro } \\
\text { padrão }\end{array}$ & Valor $\mathbf{p}$ \\
\hline PIG & Intercept & 35,0705 & 40,3525 & 0,385 \\
& MediaGlic2trim & $-0,3864$ & 0,4101 & 0,346 \\
& Ac.Urico2 & $-2,1479$ & 2,4339 & 0,378 \\
& Creat2 & 12,0093 & 12,0139 & 0,317 \\
& Ptu24h2 & 2,5663 & 2,2552 & 0,255 \\
\cline { 2 - 5 } GIG & Intercept & $-2,3724$ & 5,8322 & 0,684 \\
& MediaGlic2trim & 0,0239 & 0,0377 & 0,526 \\
& Ac.Urico2 & $-0,6211$ & 0,7255 & 0,392 \\
& Creat2 & 0,9859 & 4,3486 & 0,821 \\
& Ptu24h2 & $-1,9749$ & 2,8639 & 0,490 \\
\hline
\end{tabular}

PIG - Pequeno para a idade gestacional, GIG - Grande para a idade gestacional, MediaGlic2trim - Média glicêmica do segundo trimestre, Ac.Urico2 - Ácido Úrico no segundo trimestre, Creat2 - Creatinina sérica no segundo trimestre, Ptu24h2 - Proteinúria de 24hs no segundo trimestre.

\subsubsection{Terceiro Trimestre}

A tabela 24 demonstra os ajustes do modelo para o terceiro trimestre. 
Tabela 24 - Ajustes do modelo preditor de alterações de crescimento fetal em gestantes com DM1 para o terceiro trimestre

\section{Covariáveis}

\begin{tabular}{lrrr}
\hline PIG Intercept & 15.187 & 11.748 & .196 \\
Média Glicêmica 30 & -.238 & .144 & .098 \\
trimestre & & & \\
Ac.Urico3 & -.090 & 1.190 & .939 \\
Creat3 & 8.846 & 7.788 & .256 \\
Ptu24hs3 & -.416 & .588 & .479 \\
\hline Intercept & -3.159 & 3.606 & .381 \\
GIG Média Glicêmica 30 & .060 & .028 & .034 \\
trimestre & & & \\
Ac.Urico3 & .160 & .355 & .651 \\
Creat3 & -9.360 & 4.276 & .029 \\
Ptu24hs3 & -.175 & 1.181 & .882 \\
Ptu24hs3 & -.175 & 1.181 & .882 \\
\hline
\end{tabular}

Coeficientes Erro padrão Valor $p$

PIG - Pequeno para a idade gestacional, GIG - Grande para a idade gestacional, MediaGlic3trim - Média glicêmica do terceiro trimestre, Ac.Urico3 - Ácido Úrico no terceiro trimestre, Creat3 - Creatinina sérica no terceiro trimestre, Ptu24h3 - Proteinúria de 24hs no terceiro trimestre.

As variáveis significativas para a predição de ocorrência de feto GIG foram glicemia e creatinina. Assim, ajustamos o modelo apenas com essas covariáveis para predição de PIG e GIG. Os resultados do ajuste estão na tabela abaixo.

Tabela 25 - Ajustes do modelo preditor de alterações de crescimento fetal de acordo com os valores da média glicêmica glicemia e de creatinina sérica, no terceiro trimestre em gestantes com DM1

\begin{tabular}{ccccc}
\hline & & \multicolumn{3}{c}{ Erro } \\
\hline \multirow{2}{*}{ PIG } & Covariáveis & Coeficientes & padrão & Valor $\mathbf{p}$ \\
& Intercept & -6.5958 & 2.0261 & 0.0011 \\
& Creat3 & 4.4657 & 1.6349 & 0.0063 \\
\hline \multirow{2}{*}{ IG } & Intercept & -3.0733 & 3.4874 & 0.3782 \\
& Creat3 & -10.5872 & 3.8970 & 0.0066 \\
& MediaGlic3trim & 0.0715 & 0.0279 & 0.0104
\end{tabular}

PIG - Pequeno para a idade gestacional, GIG - Grande para a idade gestacional, MediaGlic3trim - Média glicêmica do terceiro trimestre, Creat3 Creatinina sérica no terceiro trimestre. 
Com base no ajuste, podemos determinar a probabilidade estimada de cada categoria de peso, segundo os valores da média glicêmica e de creatinina sérica, no terceiro trimestre, da seguinte maneira:

Probabilidade estimada de ser AIG:

$$
p_{1}=\frac{1}{1+\exp [-6.59+(4.46 * \text { Creat })]+\exp [-3.07-(10.58 * \text { Creat })+(0.07 * \text { Glic })]}
$$

Probabilidade estimada de ser PIG:

$$
p_{2}=\frac{\exp [-6.59+(4.46 * \text { Creat })]}{1+\exp [-6.59+(4.46 * \text { Creat })]+\exp [-3.07-(10.58 * \text { Creat })+(0.07 * \text { Glic })]}
$$

\section{Probabilidade estimada de ser GIG:}

$$
p_{3}=\frac{\exp [-3.07-(10.58 * \text { Creat })+(0.07 * \text { Glic })]}{1+\exp [-6.59+(4.46 * \text { Creat })]+\exp [-3.07-(10.58 * \text { Creat })+(0.07 * \text { Glic })]}
$$

Com base nas equações acima, calculamos as probabilidades estimadas de cada um dos indivíduos da amostra, classificando-os na categoria com maior probabilidade estimada e pode-se notar que o modelo agrupou corretamente $80.3 \%$ dos casos.

Analisando os fatores considerados preditores, a saber média glicêmica e creatinina sérica, no terceiro trimestre, foram construídas curvas de probabilidade para cada um dos desfechos. Os valores selecionados para a construção desses gráficos que exemplificam a probabilidade de classificação do RN, segundo peso e sexo no nascimento, foram escolhidos baseados na prática clínica.

\subsubsection{Curva de probabilidade de PIG, AIG e GIG, segundo o valor da média glicêmica, fixando-se $o$ valor da creatinina sérica no terceiro trimestre}


O gráfico 1 demonstra curva de probabilidade de cada desfecho, conforme os níveis de média glicêmica, no terceiro trimestre, considerandose um nível de creatinina de $0,6 \mathrm{mg} / \mathrm{dL}$.

Gráfico 1 - Curva de probabilidade de crescimento fetal em gestantes com diabetes mellitus tipo 1, a depender dos níveis de média glicêmica no terceiro trimestre, considerando-se um nível de creatinina no terceiro trimestre de $0,6 \mathrm{mg} / \mathrm{dL}$ - HC-FMUSP 2013 a 2016

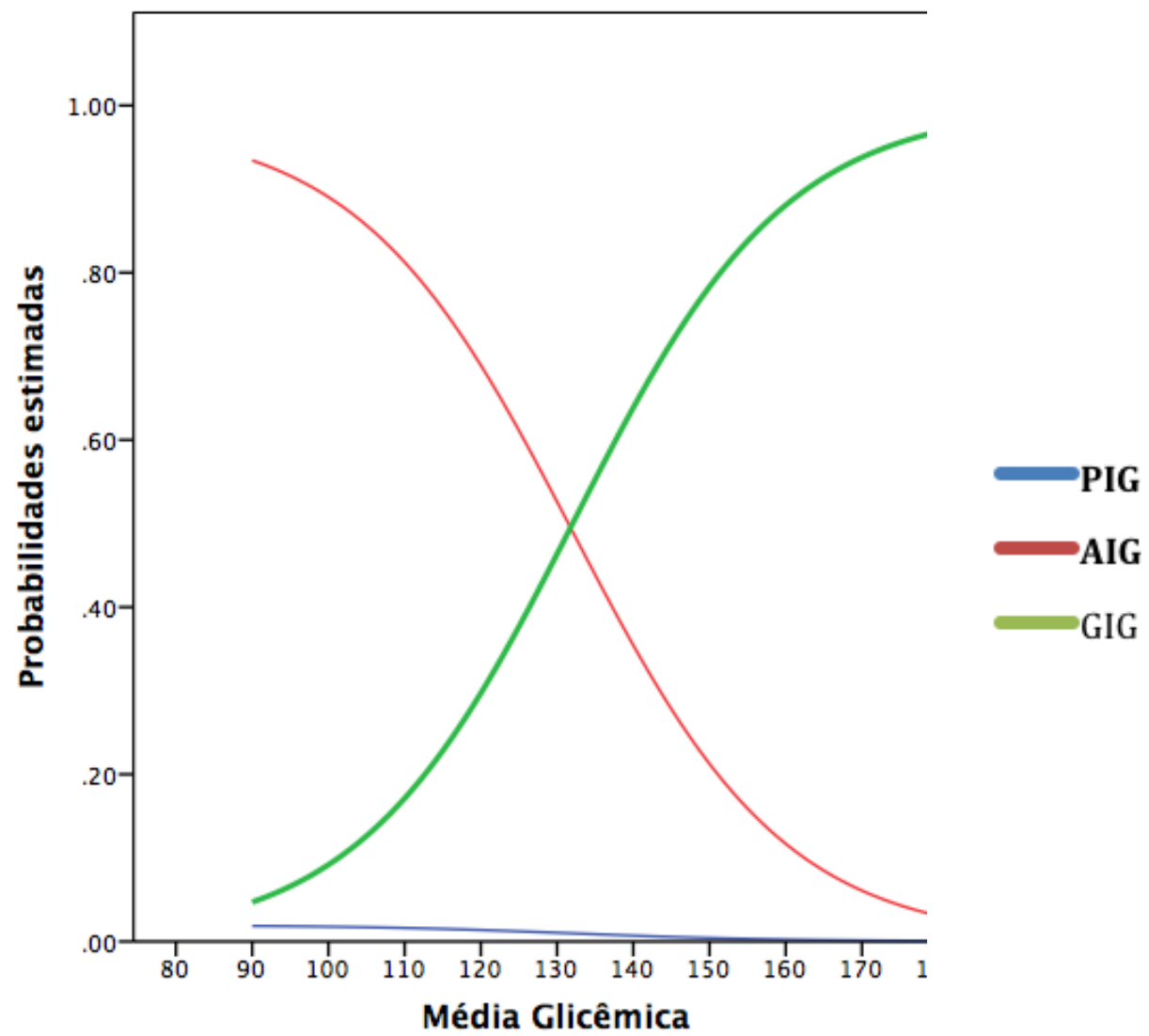

PIG - Pequeno para a idade gestacional, AIG - Adequado para a idade gestacional, GIG - Grande para a idade gestacional 
O gráfico 2 demonstra curva de probabilidade de cada desfecho, segundo os níveis de média glicêmica, no terceiro trimestre, considerando-se um nível de creatinina de $1,4 \mathrm{mg} / \mathrm{dL}$.

Gráfico 2 - Curva de probabilidade de crescimento fetal em gestantes com diabetes mellitus tipo 1, a depender dos níveis de média glicêmica no terceiro trimestre, considerando-se um nível de creatinina no terceiro trimestre de $1,4 \mathrm{mg} / \mathrm{dL}$ - HC-FMUSP 2013 a 2016



PIG - Pequeno para a idade gestacional, AIG - Adequado para a idade gestacional, GIG - Grande para a idade gestacional 
4.6.3.2. Curva de probabilidade de PIG, AIG e GIG, segundo o valor da creatinina sérica, fixando-se o valor da média glicêmica no terceiro trimestre

O gráfico 3 demonstra curva de probabilidade de cada desfecho, a depender dos níveis de creatinina sérica no terceiro trimestre, considerandose uma média glicêmica de $115 \mathrm{mg} / \mathrm{dL}$.

Gráfico 3 - Curva de probabilidade de crescimento fetal em gestantes com diabetes mellitus tipo 1 , a depender dos níveis de creatinina sérica no terceiro trimestre, considerando-se uma média glicêmica de 115 mg/dL - HC-FMUSP - 2013 a 2016

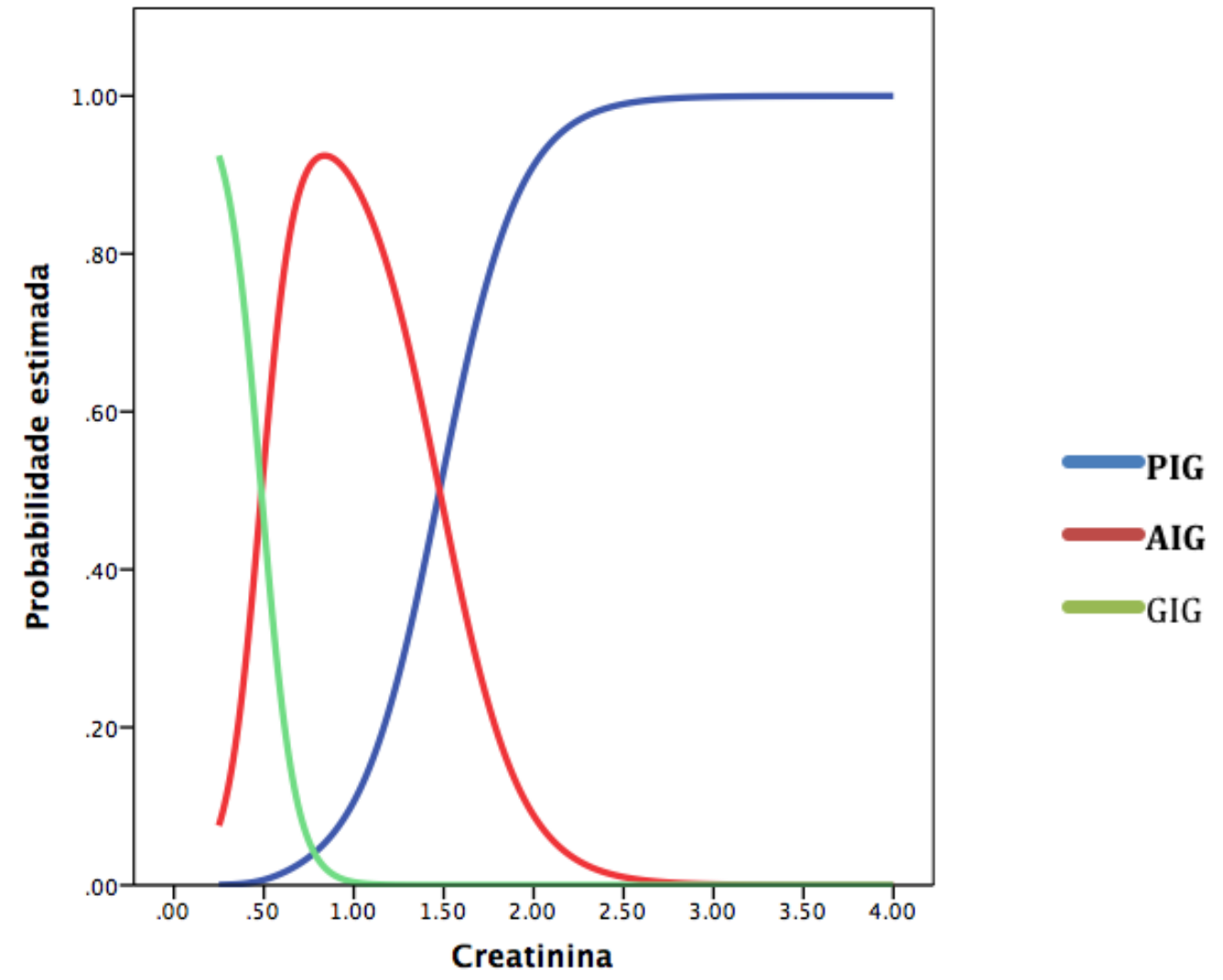

PIG - Pequeno para a idade gestacional, AIG - Adequado para a idade gestacional, GIG - Grande para a idade gestacional 
O gráfico 4 demonstra curva de probabilidade de cada desfecho, conforme os níveis de creatinina sérica no terceiro trimestre, considerando-se uma média glicêmica de $140 \mathrm{mg} / \mathrm{dL}$.

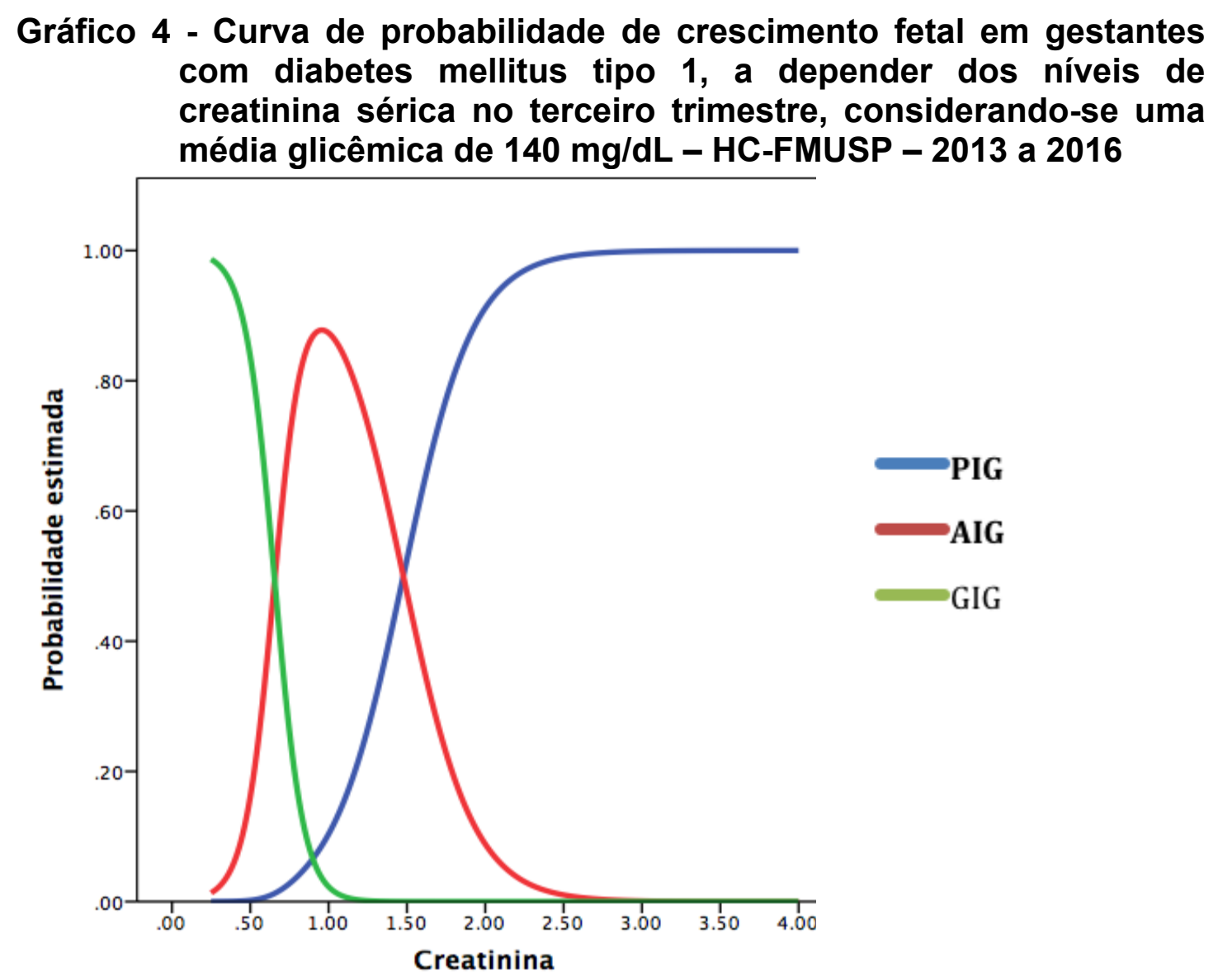


Discussão 


\section{Discussão}

O DM1 notadamente exerce forte influência sobre o crescimento fetal. Ajustar o tratamento dessa doença é importante para melhorarmos os resultados perinatais. Além disso, ao entender a sua fisiopatologia e, consequentemente, as suas complicações, passa a ser possível evitá-las e assim diminuir o impacto dessas alterações na vida adulta dos recémnascidos, visto que elas são associadas à programação metabólica fetal e, futuramente, à síndrome metabólica do adulto. ${ }^{44}$

$\mathrm{Na}$ amostra estudada, observa-se que a frequência de desvios do crescimento fetal em pacientes com DM1 ocorreu em $41 \%$ dos casos. Observa-se que 10\% das gestações resultaram em PIG e $31 \%$ em GIG e que os valores de creatinina plasmática e a média glicêmica de terceiro trimestre foram preditores desses eventos.

Apesar da frequência de PIG ser de 10\%, resultado compatível com o estimado para gestações de risco habitual, devemos considerar que a ocorrência desse evento em pacientes nas quais o esperado seria 0 crescimento fetal exagerado, pode apontar para a presença de insuficiência placentária importante, a ponto de neutralizar os efeitos da hiperglicemia materna.

Comparada com a literatura, a taxa de $31 \%$ de GIG encontrada em nossa população de pacientes com DM1 é razoável. Aschwald et al. ${ }^{24}$ relatam frequência de 57\%; Gonzales et al. ${ }^{24,45}$ a descrevem em 43\%; Kekalainen et al. ${ }^{46}$ a relatam em $52,6 \%$ e Maruotti et al. ${ }^{47}$ chegam a descrever frequência de $23,5 \%$ de fetos macrossômicos.

A elevada frequência desses desvios do crescimento, especialmente, GIG, deixa clara a importância do estudo de fatores preditores dos referidos eventos.

Apesar de utilizar amostra com número restrito de participantes ( $n=60$ em quatro anos), visto a baixa frequência dessa doença, os dados apresentados neste estudo proporcionam a consideração de uma nova perspectiva na avaliação do crescimento fetal em pacientes com DM1. 
$\mathrm{Na}$ literatura, nota-se que outros autores também encontraram dificuldades em acompanhar esse nicho específico da população de gestantes diabéticas. Para um estudo de centro único, avaliando exclusivamente DM1, o tamanho amostral é compatível com os demais descritos na literatura.

Timar et al. ${ }^{48}$, em 2014, em 6 anos de estudos na Romênia, avaliaram 94 gestantes em um centro único. Kekalainen et al. ${ }^{46}$, em 2016, em 12 anos de estudo, publicaram série com 135 gestantes com DM1 avaliadas em um centro único. Haeri et al. ${ }^{46}$, analisando 25 anos de dados (de 1978 a 1993), analisaram 340 pacientes.

Alguns fatos contribuíram ainda mais para a redução do tamanho da amostra. Dentre eles, podemos citar o início do pré-natal no primeiro trimestre e a exclusão de casos que apresentaram peptídeo $C$ normal ou aumentado.

Quanto ao início do pré-natal, no primeiro trimestre, consideramos ser essencial esse critério para que pudéssemos avaliar a relação dos marcadores laboratoriais e do controle glicêmico com o crescimento fetal durante toda a gestação. Sabe-se que, apesar das orientações para que as gestantes portadoras de DM1 planejem suas gestações e iniciem o pré-natal precocemente, em muitos casos, o início do pré-natal ainda é tardio.

Wotherspoon et al. ${ }^{49}$, em 2017 , em análise retrospectiva de dados de 747 pacientes do Diabetes and Pre-eclampsia Intervention Trial, descrevem a importância da avaliação pré-concepcional. No Reino Unido, 39\% das participantes daquele estudo tinham gestações não planejadas e tal condição, comparada às pacientes com avaliação pré-concepcional, se associou à maior frequência de fetos com peso menor que percentil 5 ( $9 \% \mathrm{x}$ $3 \%, p=0,004)$,internação do recém-nascido em unidade de terapia intensiva $(64 \% \times 50 \%, p=0,001)$ e níveis mais elevados de HbA1C durante todo o prénatal ( $\mathrm{HbA} 1 \mathrm{C}$ inicio do pré natal $-8,9 \% \times 7,7 \%, \mathrm{P}<0,005)$. Viellas et al. ${ }^{50}$, em 2014, analisaram a assistência pré-natal oferecida às gestantes usuárias de serviços de saúde públicos e/ou privados utilizando dados da pesquisa "Nascer no Brasil". Apesar de a amostra ser composta de população geral e não de um grupo exclusivo de pacientes com diabetes, chama atenção o 
número expressivo de pacientes $(24,2 \%)$ que só iniciou o pré-natal após 16 semanas.

Outro cuidado foi em relação à confirmação do diagnóstico de DM1 por meio da dosagem do peptído C. Avaliar gestantes com diabetes, sem classificá-las de forma adequada, pode comprometer o correto entendimento do comportamento da doença. Por apresentarem processo fisiopatológico completamente diferente das pacientes com outras formas de diabetes (DM2 ou DMG, por exemplo), o estudo das DM1 de maneira isolada é bastante válido. A ausência de insulina endógena, característica essencial nessas pacientes, promove evolução da doença com complicações e resultados gestacionais bastante diversos quando comparados a pacientes que apresentam hiperglicemia materna por resistência insulínica.

O peptídeo C é um complexo proteico liberado do processo de clivagem da pró-insulina endógena em insulina. Por ter meia vida mais longa e menor potencial de reação biológica, ele é utilizado para mensuração da liberação pancreática de insulina. ${ }^{22,51-54} \mathrm{Em}$ nosso estudo, mesmo ao selecionarmos somente aquelas pacientes que eram, previamente à gestação, tratadas como DM1, optamos por excluir as que apresentavam peptídeo C normal ou aumentado, garantindo que seriam incluídas somente pacientes que cursavam com insuficiência pancreática. Apesar de, atualmente, algumas das pacientes com DM1 apresentarem comportamento glicídico semelhante daquelas com perfil de resistência insulínica, resultado de uma miscelânea de comportamentos fisiopatológicos, a maioria delas apresenta padrão de glicemia bastante diferente daquelas com outras formas de diabetes. ${ }^{9}$ Assim, garantimos que as condições da amostra estudada são adequadas para o objetivo do presente estudo.

A análise das características das pacientes no início do pré-natal demonstra a semelhança entre os grupos avaliados. Chamou a atenção o fato de pacientes mais jovens serem mais frequentes no grupo GIG. Como a idade materna não é um fator que pode ser influenciado pela assistência médica, cabe considerarmos essa associação durante o julgamento clínico para que seja mais um fator de alerta para a possibilidade de crescimento fetal aumentado. 
O tempo de doença não influenciou 0 crescimento fetal. Fisiopatologicamente, o fato de as pacientes com maior tempo de doença apresentarem maior chance de vasculopatia materna, levar-nos-ia a considerá-las propensas a maior risco de PIG, entretanto, a análise absoluta desse dado não correspondeu a esse desfecho. Tal resposta pode justificarse no cuidado de assistência à paciente com DM1, concluindo que ter diabetes por muito tempo não necessariamente significaria apresentar vasculopatias, desde que ele tenha sido bem controlado e tratado. Por outro lado, pacientes com mau controle glicêmico podem apresentar vasculopatias de forma precoce. ${ }^{9}{ }^{55-57}$ As análises categóricas da presença de vasculopatias de maneira clínica, discutidas mais a frente, demonstram a associação entre alterações renais e o crescimento fetal.

Em estudos que avaliam pacientes com DM2 ou DMG, a associação entre valores de IMC mais elevados e GIG é usual, portanto, esperávamos encontrar IMC pré-gestacional mais elevado no grupo feto GIG. Porém, como o IMC médio das pacientes DM1 é, em geral, mais baixo que o da população geral (fenômeno explicado pela própria fisiopatologia da doença), diminuindo a frequência de pacientes com obesidade, tal associação não foi encontrada. A variável IMC pré-gestacional, em nosso estudo, não se correlacionou a nenhum desfecho de crescimento fetal. 9 , 10, 19, 22, 35, 38, 58-60

Nossos resultados foram semelhantes aos observados por Ulmannova et al. ${ }^{61}$, em 2014, em estudo retrospectivo de nove anos, analisando 96 gestantes com DM1. Avaliaram o impacto do índice de massa corpórea (IMC) e do HDL colesterol materno no resultado perinatal. Nesse estudo, ambas as variáveis influíram nos resultados perinatais. O HDL materno se correlacionou à ocorrência de pré-eclâmpsia $(p<0.01)$ e a diminuição de um ponto no valor do IMC reduziu em $18 \%$ a morbidade perinatal. Porém, a frequência de GIG não foi influenciada pelas variáveis estudadas.

A avaliação das intercorrências clínicas e obstétricas mostra o risco associado à gestação de pacientes com DM1. A nefropatia diabética, a hipertensão arterial crônica e a pré-eclâmpsia foram frequentemente diagnosticadas em nosso estudo. A presença de pré-eclâmpsia em mais de $30 \%$ das pacientes DM1 nos permite classificá-las como de alto risco para desenvolvimento de síndromes hipertensivas na gestação. ${ }^{\text {8, 42, 62-65 }}$ 
Outro ponto observado com essa análise foi a associação entre nefropatia e PIG. Haeri et al. ${ }^{29}$, em 2008, já correlacionaram a frequência de vasculopatias a recém-nascidos abaixo do percentil 10 de crescimento. Naquela amostra o risco relativo para PIG em pacientes com DM1 e vasculopatias comparadas a pacientes com DM1 sem vasculopatias foi de: 0,7 para aquelas com HAC; 10,4 para aquelas com retinopatia proliferativa; 1,9 para aquelas com nefropatia e de 9,9 para aquelas com nefro e retinopatias.

Com essa análise e com respaldo na recente publicação de Rolnik et al. ${ }^{66}$, em 2017, a utilização de acido acetilsalicílico, durante o pré-natal, talvez se faça necessária para todas as gestantes com DM1. No estudo citado, tal proposta diminui em $80 \%$ o risco de pré-eclâmpsia antes de 34 semanas. Adkins et al. ${ }^{67}$, também em 2017 , tentaram utilizar aspirina em baixas doses para a prevenção de PIG em 444 gestantes com diabetes pré-gestacional e vasculopatia, entretanto, tal profilaxia não se mostrou efetiva em influenciar o crescimento fetal. A gravidade da doença dessas pacientes e a conhecida associação entre o diabetes, a hiperdistensão uterina e a prematuridade é reponsável por taxas elevadas de partos antes de 37 semanas. Em nossa amostra, a frequência de partos prematuros foi de $26,7 \%$, semelhante ao descrito por Lepercq et al. ${ }^{68}$, que, em 2004, realizaram estudo de coorte com acompanhamento de 168 gestações únicas em pacientes com DM1 e observaram $24 \%$ de prematuridade (cinco vezes maior que a taxa de prematuridade em gestações únicas da população francesa no período do estudo). A HbA1c maior ou igual a $7 \%$ na época do parto foi associada à prematuridade espontânea (Odds ratio $=5,3[\mathrm{IC95} \%=1,1-26,8]$ ).

Em 2008, Ekbom et al. ${ }^{69}$ realizaram estudo prospectivo com 213 gestantes com DM1 buscando fatores preditores para prematuridade. A frequência deste desfecho no estudo citado foi de 33\%. A hemoglobina glicada foi a variável mais importante principalmente no terceiro trimestre (média no grupo prematuro $=6,7 \% \mathrm{x}$ média no grupo termo $=6,1 \%$, $p<0,001)$.

Em contrapartida, Maresh et al. ${ }^{35}$, em 2015, em estudo multicêntrico, no Reino Unido, com pacientes com DM1 que, em sua maioria, iniciaram o pré natal com $\mathrm{HbA1C}$ mais baixa que em nosso estudo, apresentaram taxa 
de prematuridade de $35,24 \%$. No estudo citado, quando analisadas somente as pacientes que iniciaram o pré-natal com $\mathrm{HbA} 1 \mathrm{C}$ acima de $7,5 \%$ (a média em nosso estudo é maior que $8 \%$ ), a taxa de prematuridade foi de $45 \%$.

Em nossa opinião, apesar do fato de a $\mathrm{HbA} 1 \mathrm{C}$ de nossas pacientes ser muito elevada, no primeiro trimestre, as taxas de prematuridade podem ter sido menores que as observadas por Maresh et al., em 2015, devido ao controle glicêmico intensivo que realizamos com elas, durante o pré-natal, o que pode ser verificado pela queda da hemoglobina glicada em todos os grupos estudados. Surpreendeu-nos o fato de as formas de padrão de crescimento fetal alterado não se associarem à prematuridade. Em nossos resultados, fetos GIG e PIG tinham idade gestacional ao nascimento semelhante a de fetos AIG, sendo necessária análise de casuística maior para melhor interpretação desses resultados.

Alguns marcadores da função renal foram escolhidos para análise nos três trimestres. A padronização de coleta de exames laboratoriais em cada um dos trimestres da gestação possibilitou o processo de comparação entre os diferentes grupos e trimestres, sendo que houve semelhança entre as idades gestacionais nos grupos estudados.

Corroborando os dados analisados de maneira categórica, a análise como variáveis lineares de marcadores diretos ou indiretos da alteração da função renal, tais como ácido úrico, creatinina sérica e proteinúria de 24 horas, em todos os trimestres, associou-se, de maneira independente, ao grupo PIG. Em nossa opinião, tais marcadores acabam por refletir de maneira diferente, o mesmo desfecho clínico de acometimento renal e provável diminuição na taxa de filtração glomerular. Assim, optamos por avaliar estes marcadores laboratoriais quantitativos para a predição do desvios do crescimento fetal em pacientes com DM1.

Nielsen et al. $^{70}$, em 2009, também encontraram piores desfechos perinatais no grupo com nefropatias, analisando de maneira prospectiva gestantes com DM1. Apesar de a amostra de pacientes com nefropatia também ter sido pequena nesse estudo (10 pacientes com microalbuminúria e sete com proteinúria), no artigo citado, os autores relatam frequência de PIG de $29 \%$ nesse grupo, versus $1 \%$ no grupo sem alteração renal. Chama a 
atenção a taxa de prematuridade descrita pelo artigo (20\% em pacientes sem alterações renais e $71 \%$ naquelas com nefropatia).

A associação entre os valores de creatinina e PIG nos faz reforçar a hipótese fisiopatológica do crescimento fetal prejudicado pela vasculopatia materna e consequente placentação inadequada. Corrobora tal linha de pensamento a maior frequência de pré-eclâmpsia no grupo AIG e PIG. Gutaj e Wender-Ozegowska ${ }^{71}$, em artigo de revisão de 2016, discutem a etiologia dessa associação. Os autores chamam a atenção para o fato de, apesar de as alterações não serem específicas dessa população, na placenta dessas pacientes, é frequente a presença de perfusão arterial materna diminuída, desenvolvimento subótimo do vilo terminal e vasculite no componente fetal.

Se as alterações da função renal associam-se à PIG, em consonância com a teoria de Pedersen e com outros estudos atuais, o controle glicêmico é considerado um dos principais determinantes do crescimento fetal exacerbado. ${ }^{16,20}$

A hemoglobina glicada é a fração da hemoglobina ligada a moléculas de glicose. Dessa forma, eleva-se à medida que a concentração da segunda aumenta. Fora do período gestacional, ela representa a média da glicêmia nos últimos 120 dias (período de meia vida das hemácias). Na gestação, diversos fatores podem influenciar a dosagem da $\mathrm{HbA} 1 \mathrm{C}$, tais como a hemodiluição fisiológica da gestação e o aumento no "turn over" de células vermelhas. Em alguns locais, é utilizada como padrão laboratorial para seguimento semanal de gestantes com diabetes (principalmente quando utilizada com sangue capilar). Porém, em nosso estudo, tanto seus valores como a dosagem de frutosamina não se associaram ao crescimento fetal. ${ }^{17}$, 27, $72-74$.

Os níveis de hemoglobina glicada que as pacientes deste estudo apresentaram no início do pré-natal demonstram a dificuldade em obter bons resultados de controle glicêmico no período pré-concepcional. Gomes et al. ${ }^{73}$,em estudo multicêntrico dos principais centros de atendimento a DM1 do Brasil, realizado com pacientes fora da gestação, constataram que somente $18,4 \%$ dos pacientes apresentavam HbA1C menor que 7\%. Em nosso estudo, as médias de $\mathrm{HbA1C}$ no primeiro trimestre, a depender do padrão de crescimento PIG, AIG ou GIG foram de 8,23; 8,11 e 8,63\% respectivamente. 
Vale ressaltar que fisiopatologicamente o crescimento fetal exagerado explica-se pelo estado anabólico provocado pela hiperinsulinemia fetal consequente à hiperglicemia sérica materna, principalmente devido a picos glicêmicos. Visto que a hiperglicemia materna, a hiperglicemia fetal e a hiperinsulinemia fetal são o eixo central do estímulo ao crescimento fetal, e que os valores da $\mathrm{HbA} 1 \mathrm{C}$ sofrem influência da gestação, esta pode não ser o parâmetro mais adequado para o seguimento desses casos.

A escolha pela avaliação da glicemia capilar, seja utilizando-se média glicêmica ou percentual de hipoglicemia ou hiperglicemia, baseia-se no fato de que com esse método consegue-se, temporalmente, avaliação melhor que a $\mathrm{HbA1C}$. A literatura médica é clara em apontar que a realização da glicemia capilar, várias vezes, durante o dia, nas pacientes diabéticas reduz complicações perinatais $^{9,30,38,75}$. Nota-se, ainda, que os resultados obtidos com glicemia capilar são semelhantes aos obtidos com tecnologias mais complexas como o real-time continuous glucose monitoring (CGMS). ${ }^{75}$

Secher et al. ${ }^{76}$, em 2013, na Dinamarca, em ensaio clínico randomizado, analisaram o impacto do uso do CGMS durante a gravidez. No estudo, 123 pacientes com DM1 e 31 com DM2 foram randomizadas para controle glicêmico com glicemia capilar sete vezes ao dia ou para, concomitantemente a essa monitorização, utilizar CGMS por seis dias com oito, 12, 21, 27 e 33 semanas de gestação. Os desfechos primários estudados foram: análise dos valores de hemoglobina glicada, controle glicêmico capilar, frequência de hipoglicemia e de GIG. Avaliando o controle glicêmico daquelas em que a gestação resultou em parto, não foram encontradas diferenças estatisticamente significativas em relação aos valores de HbA1c, média glicêmica, valores de glicemia $\leq 70 \mathrm{mg} / \mathrm{dL}$; de 70-142 $\mathrm{mg} / \mathrm{dL} ; \geq 142 \mathrm{mg} / \mathrm{dL}$. A frequência de GIG (CGMS $\mathrm{n}=34$ [45\%] x Controle $n=25$ [34\%], $p=0,19$ ) foi semelhante entre os grupos.

A média glicêmica derivada da análise da glicemia capilar, em nosso estudo, se associou a maior crescimento fetal apenas no terceiro trimestre da gestação. Considera-se que o potencial de crescimento fetal até a vigésima semana é mais influenciado pelo potencial genético fetal do que pela interação com o ambiente materno. A partir daí, teoricamente, o ambiente influencia fortemente o crescimento do feto. $\mathrm{O}$ estudo $\mathrm{HAPO}^{77}$ demonstrou, 
de maneira definitiva, em pacientes sem notável hiperglicemia patológica, que níveis mais elevados de glicose se correlacionam a resultados perinatais adversos. Assim, é possível que a média glicêmica no terceiro trimestre tenha maior relevância devido à maior velocidade de crescimento nesse trimestre.

Analisando os dados de maneira isolada, poderíamos concluir que somente o tratamento intensivo durante o terceiro trimestre seria útil para reduzir as alterações no crescimento fetal. Tal conclusão é precoce e inadequada, uma vez que, quando observada a média glicêmica nos diferentes trimestres, nota-se queda, de forma significativa, somente no grupo AIG(do primeiro para o segundo e do segundo para o terceiro trimestres), comportando-se de maneira principalmente diferente do grupo GIG (dados não apresentados).

Em nosso estudo, o desfecho crescimento fetal não se correlacionou à frequência de episódios de hipoglicemias graves. Provavelmente, isso ocorreu devido a sua baixa frequência na população estudada. Evitá-los ao máximo é essencial para uma boa assistência.

Quando analisados os dados referentes a hipoglicemias, o grupo GIG apresentou menor frequência no terceiro trimestre que o grupo PIG. Talvez, tal fenômeno ocorra pelo fato de a média glicêmica naquelas pacientes ser mais elevada e o controle glicêmico, mais trabalhoso. Considerando-se a análise geral dos grupos e dos trimestres, observamos mais episódios de hipoglicemia do que gostaríamos. Sabe-se que, no ímpeto de obter, em uma gestante e da maneira mais rápida possível, um bom controle glicêmico, muitas vezes, a agressividade na otimização do tratamento pode ser demasiada. Vale repensar a forma de reduzir a frequência das hipoglicemias, evitando-as e preservando maior segurança às pacientes, sem contudo comprometer a média glicêmica e sem elevar a frequência de hiperglicemias. A utilização de sistema de infusão contínua de insulina e insulinas de ação ultralenta formam a atual ferramenta terapêutica na abordagem de pacientes com difícil controle glicêmico às custas de hipoglicemia. Atualmente, novas formas terapêuticas têm sido utilizadas para seu controle como, por exemplo, a monitorização de glicemia intersticial contínua (CGMS) e sistemas de parada automatizada da administração de insulina que, em grupos selecionados, podem ser benéficas. ${ }^{78}$ 
Em nosso estudo, ocorreu associação entre a utilização de $\mathrm{SICl}$ e o desfecho do crescimento fetal. Todos os PIG acabaram por utilizar esse recurso, todavia, tal associação pode ser resultado de viés de seleção para uso desse dispositivo, pois as pacientes com nefropatia são as principais candidatas a essa terapêutica. Chen et al. ${ }^{79}$, em 2007, em estudo casocontrole retrospectivo com 90 gestantes com DM1, compararam os resultados perinatais e os controles glicêmicos daquelas, utilizando Sistema de Infusão Contínua de Insulina (SICI) e múltiplas doses diárias de insulina (MDDI). Nesse estudo, a frequência de alterações no crescimento fetal não dependeu do método de tratamento utilizado. Observou-se que 16/30(53\%) dos recém-nascidos foram classificados como GIG no grupo que utilizou SICI e 24/60 (40\%), no grupo com MDDI $(p=0,43)$. Já, o desfecho PIG foi observado somente em um caso $(1,6 \%)$ no grupo MDDI. A média glicêmica foi de $123 \pm 23 \mathrm{mg} / \mathrm{dL}$ no grupo $\mathrm{SICl}$ e de $128 \pm 31 \mathrm{mg} / \mathrm{dL}$ sem diferença estatisticamente significativa entre os grupos $(p=0,17)$.

Assim como o comportamento da média glicêmica, a porcentagem de hiperglicemias foi maior durante o terceiro trimestre no grupo GIG. Secher et al. $^{76}$, por exemplo, relataram porcentagens de hipoglicemia em $13 \%$ do tempo, e hiperglicemia acima de $142 \mathrm{mg} / \mathrm{dL}$ em 24\% do tempo. Apesar de encontrarem taxas de hiperglicemia semelhantes às nossas, a frequência de GIG nessa população foi maior que a encontrada pelo nosso estudo.

Apesar disso, a frequência de hiperglicemia acima de 200 mg/dL não se correlacionou ao desfecho de crescimento (por exemplo, durante o terceiro trimestre: PIG - 2,47\%, AIG - 3,76\%, GIG - 7,02\%; p = 0,078), diferente do observado por Damm et al. $^{25}$, em 2014, que referem que a frequência de GIG e de macrossomia foi maior na presença de glicemia plasmática acima de $198 \mathrm{mg} / \mathrm{dL}$.

Tal comportamento corrobora o mecanismo fisiopatológico envolvido no crescimento fetal exagerado, que aponta a importância do terceiro trimestre no crescimento fetal. Porém, a análise de todos esses dados nos diferentes trimestres permitiu a observação do impacto do tratamento no controle glicêmico dessas mulheres durante toda a gestação.

Fica claro, até este momento, a relação entre marcadores laboratoriais da função renal e PIG, assim como a importância da hiperglicemia no terceiro 
trimestre e a ocorrência de GIG. No entanto, no seguimento de gestantes com DM1, estes fatores costumam coexistir, sendo necessária uma análise que permita observar esses parâmetros simultaneamente e assim predizer os desvios do crescimento fetal. A análise dos fatores preditores para os padrões de crescimento traz novos dados para a literatura médica da área. Objetivando-se, inicialmente, estudar as alterações glicêmicas que seriam preditoras de alterações do crescimento fetal para ajustarmos nossos alvos glicêmicos, principalmente para o grupo GIG, foi surpreendente encontrar um padrão bem estabelecido para o crescimento fetal baseado em alterações renais, representado pela alteração nos níveis de creatinina sérica.

A creatinina sérica, quando aumentada, influencia o crescimento fetal em sentido à sua restrição. Apesar de a taxa de PIG ter sido a esperada na população normal (10\%), chama a atenção o fato que quando os valores de creatinina são fixados em $1,4 \mathrm{mg} / \mathrm{dL}$, a média glicêmica passa a não influenciar o crescimento fetal. Tal resultado nos leva a pensar se não seria adequado reajustar o alvo glicêmico para níveis mais elevados, uma vez que as pacientes com alterações na função renal classicamente apresentam maior probabilidade de hipoglicemia, visto que a insulina tem metabolização renal e o desfecho PIG parece não ser influenciado pelos valores da média glicêmica no terceiro trimestre. ${ }^{24}$ Porém, outro fato precisa ser avaliado relacionando-se às complicações da hiperglicemia que se sobrepõem àquelas encontradas em PIG como maior frequência de hipoglicemia neonatal, icterícia, prematuridade e sofrimento fetal.

A avaliação específica desses fatores se faz necessária. Infelizmente, a validação dessas hipóteses depende de ensaios clínicos randomizados com pacientes DM1 nefropatas, condição razoavelmente rara em um centro único, o que praticamente inviabiliza a pesquisa nessas circunstâncias, apontando para a necessidade de estudos multicêntricos. Nielsen et al, em 2009, também encontraram dificuldade em selecionar essas pacientes. No estudo citado, que objetivava analisar os resultados perinatais e as terapêuticas anti-hipertensivas em gestantes com DM1 e nefropatia, de 117 pacientes, somente 10 apresentavam microalbuminúria e sete, nefropatia franca. 
Em relação à média glicêmica, no terceiro trimestre, à medida que seus valores aumentam, a probabilidade de GIG acompanha esse movimento, quando os valores de creatinina são normais. Na análise da média glicêmica, considerando-se valores de creatinina de 0,6 mg/dL, para mantermos as taxas de GIG semelhantes a que tivemos neste estudo (31\%), precisaremos conservar médias glicêmicas de $120 \mathrm{mg} / \mathrm{dL}$. Para a redução da frequência de GIG para 20\%, a média glicêmica deveria estar próxima a $115 \mathrm{mg} / \mathrm{dL}$. Para taxas semelhantes as da população geral, 10\%, são necessárias médias glicêmicas de $100 \mathrm{mg} / \mathrm{dL}$. Nota-se que, considerando os valores máximos preconizados pela $\mathrm{ADA}^{9}$, a média glicêmica seria de $116 \mathrm{mg} / \mathrm{dL}$, o que corresponderia a uma probabilidade de $20 \%$ de ocorrência de GIG. Porém, os desafios para controlar a hiperglicemia nas pacientes com DM1 esbarram no risco de hipoglicemia e suas consequências a curto e longo prazo.

É importante observar que, a despeito do número restrito de casos deste estudo e da baixa frequência de PIG, ao realizar o pós-teste, aplicandose as fórmulas determinadas para a predição de PIG, AIG e GIG, o modelo classificou corretamente $80,3 \%$ dos casos, mostrando-se ferramenta útil para a predição dos desvios de crescimento em pacientes com DM1.

Conclui-se, assim, que é necessário buscar novos valores de média glicêmica com o objetivo de reduzir a ocorrência de GIG. Há, porém, pontos a serem estudados que merecem atenção. É necessário encontrar formas de reduzir a ocorrência de PIG em pacientes nefropatas e principalmente melhorar o controle glicêmico materno, especialmente no terceiro trimestre, reduzindo-se a média glicêmica com segurança, evitando-se a hipoglicemia. Nesse sentido, é importante que os avanços alcançados para não gestantes possam ser estendidos às gestantes. Acreditamos que a utilização de novas insulinas, como a degludeca, que leva à redução de hipoglicemias, possa ser uma opção, no futuro, para gestantes portadoras de DM1. Novos estudos encontram-se em andamento sobre o tema.

Conclui-se, assim, que apesar de ser clara a associação entre o controle glicêmico e o crescimento fetal, as alta taxas de GIG e PIG em gestações de portadoras de DM1 demonstram claramente que o assunto ainda não está esgotado e que muitos estudos ainda são necessários para 
atingirmos os melhores resultados em relação ao crescimento fetal nesse grupo de pacientes. 
Conclusões 


\section{Conclusões}

O presente estudo que avaliou gestações de pacientes portadoras de diabetes mellitus tipo 1 permitiu concluir que:

A frequência de PIG, AIG e GIG foi de 10\%, 58,3\% e 31,7\%, respectivamente;

A média glicêmica, a porcentagem de hipoglicemias e de hiperglicemias no terceiro trimestre, se associou a GIG;

Houve associação, em todos os trimestres, entre os marcadores de função renal materna (valores de ácido úrico, proteinúria de 24 horas e creatinina sérica) e PIG.

Foi possível predizer a classificação do peso do RN, segundo idade gestacional e sexo, utilizando os valores de creatinina plasmática e a média glicêmica no terceiro trimestre. 
Anexos 


\section{Anexo A - Aprovação da Comissão de Ética para Análise de Projetos de Pesquisa - CAPPesq - do Hospital das Clínicas da Faculdade de Medicina da Universidade de São Paulo}

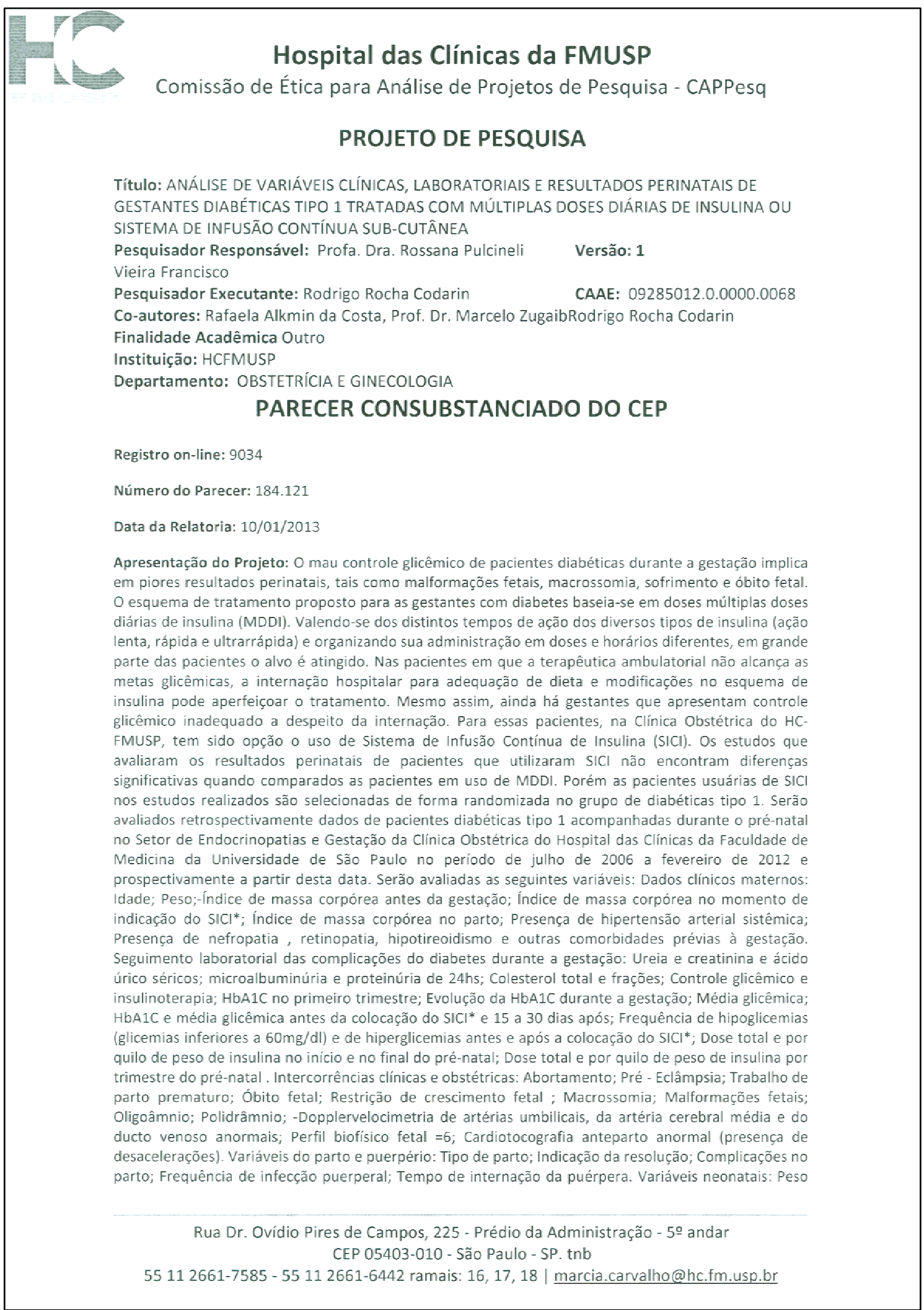




\section{Hospital das Clínicas da FMUSP}

\section{Comissão de Ética para Análise de Projetos de Pesquisa - CAPPesq}

no nascimento; Idade gestacional do parto; Classificação do peso no nascimento ; Índices de Apgar de 1ㅇ, 5․ e 10․ Minuto; $\mathrm{pH}$ do sangue da artéria umbilical no nascimento; Ocorrência de hipoglicemia, icterícia, desconforto respiratório e hipocalcemia neonatal ; Intubação oro-traqueal na sala de parto; Admissão em UTI neonatal; Tempo de internação do RN; Mortalidade neonatal.

Objetivo da Pesquisa: Analisar dados clínicos e laboratoriais, e resultados perinatais, de pacientes diabéticas tipo 1, acompanhadas na Clínica Obstétrica do HC-FMUSP, que fizeram uso de $\mathrm{SICl}$ na gestação e compará-los ao de portadoras de diabetes tipo 1 que não tiveram indicação de uso de SICI durante a gravidez.

Avaliação dos Riscos e Benefícios: $O$ estudo é observacional e não haverá interferência no tratamento das participantes da pesquisa, que serão abordadas segundo os protocolos já estabelecidos. Há poucos benefícios para as participantes da pesquisa, mas os benefícios para o grupo de gestantes com diabetes tipo1 poderá ser grande se houver a comprovação dos benefícios da infusão contínua de insulina.

Comentários e Considerações sobre a Pesquisa: Estudo observacional, com duas partes, a primeira retrospectiva, a partir de prontuários de participantes já atendidas na Clínica Obstétrica e a segunda prospectiva, com duração de 05 anos. O estudo está metodologicamente correto. TCLE claro e objetivo, de fácil entendimento.

Considerações sobre os Termos de apresentação obrigatória: Preenchidos adequadamente.

Recomendações: Solicita-se a atualização do currículo Lattes do Dr. Rodrigo Rocha Codarin e dos telefones da CAPPesq no TCLE.

Conclusões ou Pendências e Lista de Inadequações: Estudo observacional elaborado corretamente do ponto de vista metodológico e ético, não havendo empecilhos para a sua aprovação.

Situação do Parecer: Aprovado

Necessita Apreciação da CONEP: Não

Considerações Finais a critério do CEP: Aprovado



Rua Dr. Ovídio Pires de Campos, 225 - Prédio da Administração - 50 andar CEP 05403-010 - São Paulo - SP. tnb

5511 2661-7585 - 5511 2661-6442 ramais: 16, 17, 18 | marcia.carvalho@hc.fm.usp.br 
Anexo B - Modelo do termo de consentimento livre e esclarecido

HOSPITAL DAS CLÍNICAS DA FACULDADE DE MEDICINA DA UNIVERSIDADE DE SÃO PAULO-HCFMUSP

TERMO DE CONSENTIMENTO LIVRE E ESCLARECIDO

\section{- DADOS DE IDENTIFICAÇÃO DO SUJEITO DA PESQUISA OU \\ RESPONSÁVEL LEGAL}

1. NOME:

DOCUMENTO DE IDENTIDADE NN :

SEXO :.$M \square \quad F$

DATA NASCIMENTO: ........................

ENDEREÇO

$\mathrm{N}^{\circ}$

APTO:

BAIRRO:

CIDADE

CEP:

TELEFONE:DDD (

..)

2.RESPONSÁVEL LEGAL

NATUREZA (grau de parentesco, tutor, curador etc.)

DOCUMENTO DE IDENTIDADE : SEXO: $M \square \quad F \square$

DATA NASCIMENTO.: ....................

ENDEREÇO:

$\mathrm{N}^{\circ}$

APTO:

BAIRRO:

TELEFONE: DDD (

CIDADE:

CEP:

DADOS SOBRE A PESQUISA

1. TÍTULO DO PROTOCOLO DE PESQUISA Análise de variáveis clínicas, laboratoriais e resultados perinatais de gestantes diabéticas tipo 1 tratadas com múltiplas doses diárias de insulina ou sistema de infusão contínua sub-cutânea

PESQUISADOR : ROSSANA PULCINELI VIEIRA FRANCISCO

CARGO/FUNÇÃO: PROFESSORA ASSOCIADA DA DISCIPLINA DE OBSTETRÍCIA DA UNIVERSIDADE DE SÃO PAULO

INSCRIÇÃO CONSELHO REGIONAL No 75535

UNIDADE DO HCFMUSP: DIVISÃO DE CLINICA OBSTETRICA DO HOSPITAL DAS CLÍNICAS DA FACULDADE DE MEDICINA DA USP 
3. AVALIAÇÃO DO RISCO DA PESQUISA:

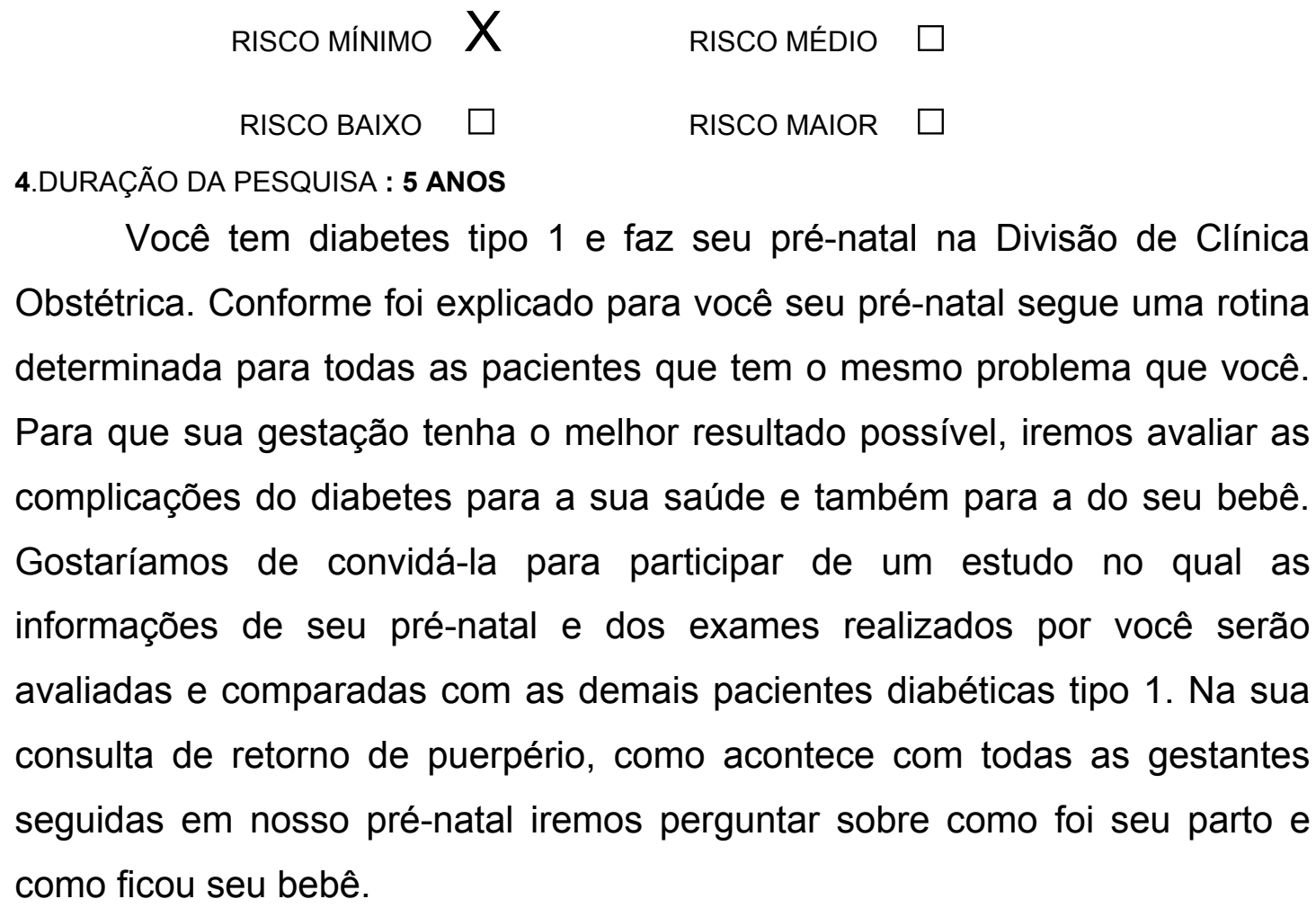

Nessa pesquisa não há risco e benefícios para você mas os resultados obtidos poderão ajudar a melhorar cada vez mais a assistência pré-natal de mulheres diabéticas.

Em qualquer etapa do estudo, você terá acesso aos profissionais responsáveis pela pesquisa para esclarecimento de eventuais dúvidas. A principal investigadora é a Dra. Rossana Pulcineli Vieira Francisco, que pode ser encontrada no endereço Rua Dr. Enéas de Carvalho Aguiar, 255, $10^{\circ}$ andar, telefone: (11) 2661-6209. Se você tiver alguma consideração ou dúvida sobre a ética da pesquisa, entre em contato com o Comitê de Ética em Pesquisa (CEP) - Rua Ovídio Pires de Campos, 225 - 5 andar - tel: 2661-6442 ramais 16, 17, 18 ou 20 - e-mail: cappesq.adm@ @c.fm.usp.br

É garantida a liberdade da retirada de consentimento a qualquer momento e deixar de participar do estudo, sem qualquer prejuízo à continuidade de seu tratamento na Instituição. As informações obtidas serão analisadas em conjunto com outras pacientes, não sendo divulgada a identificação de nenhuma paciente. Você tem o direito de ser mantida atualizada sobre os resultados parciais das pesquisas, quando em estudos abertos, ou de resultados que sejam do conhecimento dos pesquisadores.

Não há despesas pessoais para a participante em qualquer fase do estudo, incluindo exames e consultas. Também não há compensação financeira relacionada à sua 
participação. Se existir qualquer despesa adicional, ela será absorvida pelo orçamento da pesquisa.

Os pesquisadores se comprometem a utilizar os dados e o material coletado somente para esta pesquisa.

Acredito ter sido suficientemente informado a respeito das informações que li ou que foram lidas para mim, descrevendo o estudo" Análise de variáveis clínicas, laboratoriais e resultados perinatais de gestantes diabéticas tipo 1 tratadas com múltiplas doses diárias de insulina ou sistema de infusão contínua sub-cutânea

Eu discuti com a pesquisadora Rossana Pulcineli Vieira Francisco sobre a minha decisão em participar nesse estudo. Ficaram claros para mim quais são os propósitos do estudo, os procedimentos a serem realizados, seus desconfortos e riscos, as garantias de confidencialidade e de esclarecimentos permanentes. Ficou claro também que minha participação é isenta de despesas e que tenho garantia do acesso a tratamento hospitalar quando necessário. Concordo voluntariamente em participar deste estudo e poderei retirar o meu consentimento a qualquer momento, antes ou durante $o$ mesmo, sem penalidades ou prejuízo ou perda de qualquer benefício que eu possa ter adquirido, ou no meu atendimento neste Serviço.

Data

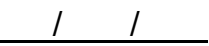

Assinatura da testemunha

Data

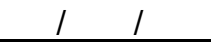

para casos de pacientes menores de 18 anos, analfabetos, semi-analfabetos ou portadores de deficiência auditiva ou visual.

\section{(Somente para o responsável do projeto)}

Declaro que obtive de forma apropriada e voluntária o Consentimento Livre e Esclarecido deste paciente ou representante legal para a participação neste estudo. 
Referências 


\section{REFERÊNCIAS}

1. Gabbe SG, Graves CR. Management of diabetes mellitus complicating pregnancy. Obstet Gynecol. 2003 Oct;102(4):857-68. PubMed PMID: 14551019. eng.

2. Jain S, Saraf S. Type 2 diabetes mellitus-Its global prevalence and therapeutic strategies. Diabetes \& Metabolic Syndrome: Clinical Research \& Reviews. 2010 1//;4(1):48-56.

3. 2. Classification and Diagnosis of Diabetes. Diabetes Care. 2016 2016-0101 00:00:00;39(Supplement 1):S13-S22.

4. Garner P. Type I diabetes mellitus and pregnancy. Lancet. 1995 Jul 15;346(8968):157-61. PubMed PMID: 7603233. Epub 1995/07/15. eng.

5. Vargas R, Repke JT, Ural SH. Type 1 Diabetes Mellitus and Pregnancy. Reviews in Obstetrics and Gynecology. 2010 Summer;3(3):92-100. PubMed PMID: PMC3046748.

6. Lisboa HR, Graebin R, Butzke L, Rodrigues CS. Incidence of type 1 diabetes mellitus in Passo Fundo, RS, Brazil. Braz J Med Biol Res. 1998 Dec;31(12):1553-6. PubMed PMID: 9951551. Epub 1999/02/10. eng.

7. Negrato CA, Dias JP, Teixeira MF, Dias A, Salgado MH, Lauris JR, et al. Temporal trends in incidence of Type 1 diabetes between 1986 and 2006 in Brazil. J Endocrinol Invest. 2010 Jun;33(6):373-7. PubMed PMID: 19620822. Epub 2009/07/22. eng.

8. Coutinho WF, Silva Junior WS. Diabetes Care in Brazil. Ann Glob Health. 2015 Nov-Dec;81(6):735-41. PubMed PMID: 27108141. Epub 2016/04/25. eng.

9. Standards of Medical Care in Diabetes-2017: Summary of Revisions. Diabetes Care. 2017 Jan;40(Suppl 1):S4-s5. PubMed PMID: 27979887. Epub 2016/12/17. eng.

10. McCance DR. Diabetes in pregnancy. Best Pract Res Clin Obstet Gynaecol. 2015 Jul;29(5):685-99. PubMed PMID: 26004196. Epub 2015/05/26. eng.

11. Kirwan JP, Hauguel-De Mouzon S, Lepercq J, Challier JC, Huston-Presley L, Friedman JE, et al. TNF-alpha is a predictor of insulin resistance in human pregnancy. Diabetes. 2002 Jul;51(7):2207-13. PubMed PMID: 12086951. Epub 2002/06/28. eng.

12. Kafalidis G, Boutsikou T, Briana DD, Boutsikou M, Marmarinos A, Baka S, et al. Adipokines vaspin and omentin-1 are up-regulated in large for gestational age infants at term. Cytokine. 2013 Apr;62(1):70-4. PubMed PMID: 23490415. Epub 2013/03/16. eng.

13. Mestman JH. Historical Notes on Diabetes and Pregnancy. The Endocrinologist. 2002;12(3):224-42. PubMed PMID: 00019616-20020500000010 .

14. Holmes VA, Young IS, Patterson CC, Pearson DW, Walker JD, Maresh MJ, et al. Optimal glycemic control, pre-eclampsia, and gestational hypertension in women with type 1 diabetes in the diabetes and pre-eclampsia intervention trial. Diabetes Care. 2011 Aug;34(8):1683-8. PubMed PMID: 21636798. Pubmed Central PMCID: PMC3142058. eng.

15. Pedersen J, Molsted-Pedersen LM. Congenital malformations: the possible role of diabetes care outside pregnancy. Ciba Found Symp. 1978 Mar 30-Apr 1(63):265-71. PubMed PMID: 256545. Epub 1978/03/01. eng. 
16. Pedersen J. Weight and length at birth of infants of diabetic mothers. Acta Endocrinol (Copenh). 1954 Aug;16(4):330-42. PubMed PMID: 13206643. Epub 1954/08/01. eng.

17. Negrato CA, Mattar R, Gomes MB. Adverse pregnancy outcomes in women with diabetes. Diabetol Metab Syndr. 2012;4(1):41. PubMed PMID: 22964143. Pubmed Central PMCID: Pmc3514247. Epub 2012/09/12. eng.

18. Jovanovic L, Nakai Y. Successful Pregnancy in Women with Type 1 Diabetes: From Preconception Through Postpartum Care. Endocrinology and Metabolism Clinics.35(1):79-97.

19. Catalano PM, Hauguel-De Mouzon S. Is it time to revisit the Pedersen hypothesis in the face of the obesity epidemic? Am J Obstet Gynecol. 2011 Jun;204(6):479-87. PubMed PMID: 21288502. Pubmed Central PMCID: Pmc3130827. Epub 2011/02/04. eng.

20. Pedersen J. Diabetes and pregnancy; blood sugar of newborn infants during fasting and glucose administration. Nord Med. 1952 Jul 25;47(30):1049. PubMed PMID: 14948109. Epub 1952/07/25. eng.

21. Pedersen J, Brandstrup E. Fetal mortality in pregnant diabetics. Lancet. 1956;27.

22. Codarin RR, Francisco RPV. A gestante com diabetes mellitus tipo 1. In: Zugaib M, Bittar RE, Francisco RPV, editors. Protocolos Assistenciais da Clínica Obstétrica da Faculdade de Medicina da Universidade de São Paulo2015.

23. The effect of intensive treatment of diabetes on the development and progression of long-term complications in insulin-dependent diabetes mellitus. The Diabetes Control and Complications Trial Research Group. N Engl J Med. 1993 Sep 30;329(14):977-86. PubMed PMID: 8366922. Epub 1993/09/30. eng.

24. Aschwald CL, Catanzaro RB, Weiss EP, Gavard JA, Steitz KA, Mostello DJ. Large-for-gestational-age infants of type 1 diabetic mothers: an effect of preprandial hyperglycemia? Gynecol Endocrinol. 2009 Oct;25(10):653-60. PubMed PMID: 19544119. Epub 2009/06/23. eng.

25. Damm P, Mersebach H, Rastam J, Kaaja R, Hod M, McCance DR, et al. Poor pregnancy outcome in women with type 1 diabetes is predicted by elevated HbA1c and spikes of high glucose values in the third trimester. J Matern Fetal Neonatal Med. 2014 Jan;27(2):149-54. PubMed PMID: 23687948. Pubmed Central PMCID: Pmc3877859. Epub 2013/05/22. eng.

26. Desoye G, Nolan CJ. The fetal glucose steal: an underappreciated phenomenon in diabetic pregnancy. Diabetologia. 2016 Jun;59(6):1089-94. PubMed PMID: 26995651. Pubmed Central PMCID: Pmc4861753. Epub 2016/03/21. eng.

27. Kekalainen P, Juuti M, Walle T, Laatikainen T. Pregnancy planning in type 1 diabetic women improves glycemic control and pregnancy outcomes. J Matern Fetal Neonatal Med. 2015 Sep 11:1-7. PubMed PMID: 26364952. Epub 2015/09/15. Eng.

28. Howarth C, Gazis A, James D. Associations of Type 1 diabetes mellitus, maternal vascular disease and complications of pregnancy. Diabetic Medicine. 2007;24(11):1229-34.

29. Haeri S, Khoury J, Kovilam O, Miodovnik M. The association of intrauterine growth abnormalities in women with type 1 diabetes mellitus complicated by vasculopathy. Am J Obstet Gynecol. 2008 Sep;199(3):278.e1-5. PubMed PMID: 18771982. Epub 2008/09/06. eng. 
30. Durackova L, Kristufkova A, Korbel M. Pregnancy and neonatal outcomes in women with type 1 diabetes mellitus. Bratisl Lek Listy. 2017;118(1):56-60. PubMed PMID: 28127984. Epub 2017/01/28. eng.

31. Mello G, Parretti E, Mecacci F, La Torre P, Cioni R, Cianciulli D, et al. What degree of maternal metabolic control in women with type 1 diabetes is associated with normal body size and proportions in full-term infants? Diabetes Care. 2000 Oct;23(10):1494-8. PubMed PMID: 11023142. Epub 2000/10/07. eng.

32. Herranz L, Pallardo LF, Hillman N, Martin-Vaquero P, Villarroel A, Fernandez A. Maternal third trimester hyperglycaemic excursions predict largefor-gestational-age infants in type 1 diabetic pregnancy. Diabetes Research and Clinical Practice. 2007 2007/01/01/;75(1):42-6.

33. Persson M, Pasupathy D, Hanson U, Norman M. Birth Size Distribution in 3,705 Infants Born to Mothers With Type 1 Diabetes. A population-based study. 2011;34(5):1145-9.

34. Feitosa AC, Andrade FS. [Evaluation of fructosamine as a parameter of blood glucose control in diabetic pregnant women]. Arq Bras Endocrinol Metabol. 2014 Oct;58(7):724-30. PubMed PMID: 25372581. Epub 2014/11/06. Avaliacao da frutosamina como parametro de controle glicemico na gestante diabetica. por.

35. Maresh MJ, Holmes VA, Patterson CC, Young IS, Pearson DW, Walker JD, et al. Glycemic targets in the second and third trimester of pregnancy for women with type 1 diabetes. Diabetes Care. 2015 Jan;38(1):34-42. PubMed PMID: 25368104. Epub 2014/11/05. eng.

36. Cahill AG, Tuuli MG, Colvin R, Cade WT, Macones GA. Markers of Glycemic Control and Neonatal Morbidity in High-Risk Insulin-Resistant Pregnancies. Am J Perinatol. 2016 Jan;33(2):151-6. PubMed PMID: 26332585. Epub 2015/09/04. eng.

37. Mehta S, Khoury J, Miodovnik M, Kawakita T, Ehrlich S, Bowers K. Placental Weight in Pregnant Women with Type 1 Diabetes Mellitus: The Association with Fetal Growth. Am J Perinatol. 2016 Nov;33(13):1255-61. PubMed PMID: 27398699. Epub 2016/10/21. eng.

38. Gupta R, Khoury J, Altaye M, Dolan L, Szczesniak RD. Glycemic Excursions in Type 1 Diabetes in Pregnancy: A Semiparametric Statistical Approach to Identify Sensitive Time Points during Gestation. Journal of Diabetes Research.

;2017:2852913. PubMed PMID: PMC5320381.

39. Gutaj P, Wender-Ożegowska E, Brązert J. Maternal lipids associated with large-for-gestational-age birth weight in women with type 1 diabetes: results from a prospective single-center study. Archives of Medical Science : AMS. 2017 ;13(4):753-9. PubMed PMID: PMC5510499.

40. Codarin RR, Francisco RPV. Diabetes Mellitus tipo 1. In: Zugaib M, Bittar RE, Francisco RPV, editors. Protocolos Assistenciais Clínica Obstétrica FMUSP. 5a ed. São Paulo: Editora Atheneu; 2015. p. 225-38.

41. Fenton TR, Kim JH. A systematic review and meta-analysis to revise the Fenton growth chart for preterm infants. BMC Pediatrics. 2013;13(1):1-13.

42. Tranquilli AL, Dekker G, Magee L, Roberts J, Sibai BM, Steyn W, et al. The classification, diagnosis and management of the hypertensive disorders of pregnancy: A revised statement from the ISSHP. Pregnancy Hypertension: An International Journal of Women's Cardiovascular Health. 2014 4//;4(2):97-104. 
43. Agresti A. Logit Models for Multinomial Responses. Categorical Data Analysis: John Wiley \& Sons, Inc.; 2003. p. 267-313.

44. Barker DJ, Thornburg KL. Placental programming of chronic diseases, cancer and lifespan: a review. Placenta. 2013 Oct;34(10):841-5. PubMed PMID: 23916422. Epub 2013/08/07. eng.

45. Gonzalez Blanco C, Chico Ballesteros A, Gich Saladich I, Corcoy Pla R. Glycemic control and pregnancy outcomes in women with type 1 diabetes mellitus using lispro versus regular insulin: a systematic review and metaanalysis. Diabetes Technol Ther. 2011 Sep;13(9):907-11. PubMed PMID: 21714679. Epub 2011/07/01. eng.

46. Kekalainen P, Juuti M, Walle T, Laatikainen T. Continuous Subcutaneous Insulin Infusion During Pregnancy in Women with Complicated Type 1 Diabetes Is Associated with Better Glycemic Control but Not with Improvement in Pregnancy Outcomes. Diabetes Technol Ther. 2016 Mar;18(3):144-50. PubMed PMID: 26502287. Epub 2015/10/27. eng.

47. Maruotti GM, Rizzo G, Sirico A, Sarno L, Cirigliano L, Arduini D, et al. Are there any relationships between umbilical artery Pulsatility Index and macrosomia in fetuses of type I diabetic mothers? J Matern Fetal Neonatal Med. 2014 Nov;27(17):1776-81. PubMed PMID: 24397275. Epub 2014/01/09. eng.

48. Timar B, Timar R, Albai A, Stoian D, Nitu R, Craina M. Predictors for pregnancy outcomes in Romanian women with Type 1 Diabetes Mellitus: a prospective study. Diabetol Metab Syndr. 2014;6(1):125. PubMed PMID: 25435920. Pubmed Central PMCID: Pmc4247610. Epub 2014/12/02. eng.

49. Wotherspoon AC, Young IS, Patterson CC, McCance DR, Holmes VA. Effect of pregnancy planning on maternal and neonatal outcomes in women with Type 1 diabetes. 2017 Sep;34(9):1303-8. PubMed PMID: 28586549.

50. Viellas EF, Domingues RMSM, Dias MAB, Gama SGNd, Theme Filha MM, Costa JVd, et al. Assistência pré-natal no Brasil. Cadernos de Saúde Pública. 2014;30:S85-S100.

51. Wilcox NS, Rui J, Hebrok M, Herold KC. Life and death of beta cells in Type 1 diabetes: A comprehensive review. J Autoimmun. 2016 Mar 23. PubMed PMID: 27017348. Epub 2016/03/28. Eng.

52. Otto-Buczkowska E. [The clinical utility of C-peptide measurement in diabetology]. Pediatr Endocrinol Diabetes Metab. 2015;20(2):63-8. PubMed PMID: 26615015. Epub 2015/11/29. Przydatnosc oznaczania peptydu C w diabetologii. pol.

53. Jones AG, Hattersley AT. The clinical utility of C-peptide measurement in the care of patients with diabetes. Diabet Med. 2013 Jul;30(7):803-17. PubMed PMID: 23413806. Pubmed Central PMCID: Pmc3748788. Epub 2013/02/19. eng. 54. Nielsen LR, Rehfeld JF, Pedersen-Bjergaard U, Damm P, Mathiesen ER. Pregnancy-induced rise in serum C-peptide concentrations in women with type 1 diabetes. Diabetes Care. 2009 Jun;32(6):1052-7. PubMed PMID: 19244092. Pubmed Central PMCID: Pmc2681014. Epub 2009/02/27. eng.

55. Amiel SA, Pursey N, Higgins B, Dawoud D. Diagnosis and management of type 1 diabetes in adults: summary of updated NICE guidance. Bmj. 2015;351:h4188. PubMed PMID: 26311706. Epub 2015/08/28. eng.

56. Effect of intensive diabetes treatment on albuminuria in type 1 diabetes: long-term follow-up of the Diabetes Control and Complications Trial and Epidemiology of Diabetes Interventions and Complications study. Lancet 
Diabetes Endocrinol. 2014 Oct;2(10):793-800. PubMed PMID: 25043685. Pubmed Central PMCID: Pmc4215637. Epub 2014/07/22. eng.

57. Fullerton B, Jeitler K, Seitz M, Horvath K, Berghold A, Siebenhofer A. Intensive glucose control versus conventional glucose control for type 1 diabetes mellitus. Cochrane Database Syst Rev. 2014;2:Cd009122. PubMed PMID: 24526393. Epub 2014/02/15. eng.

58. Temple R, Murphy $\mathrm{H}$. Type 2 diabetes in pregnancy - An increasing problem. Best Practice \& Research Clinical Endocrinology \& Metabolism. 2010 8//;24(4):591-603.

59. Madan J, Chen M, Goodman E, Davis J, Allan W, Dammann O. Maternal obesity, gestational hypertension, and preterm delivery. J Matern Fetal Neonatal Med. 2010 Jan;23(1):82-8. PubMed PMID: 19903115. Epub 2009/11/12. eng.

60. Aly H, Hammad T, Nada A, Mohamed M, Bathgate S, El-Mohandes A. Maternal obesity, associated complications and risk of prematurity. J Perinatol. 2010 Jul;30(7):447-51. PubMed PMID: 19693021. Epub 2009/08/21. eng.

61. Ulmannova T, Bartaskova D, Spalova I, Zoban P, Vesely Z, Stechova K. Maternal BMI and HDL as predictors of pregnancy outcome in women with type 1 diabetes. J Matern Fetal Neonatal Med. 2014 Oct;27(15):1580-3. PubMed PMID: 24298876. Epub 2013/12/05. eng.

62. Haghighi L, Nasiri N, Ebrahimi A, Najmi Z, Moradi Y, Hashemi N. Predictive value of 4-, 8-, and 12-h urine protein and protein-to-creatinine ratio for detection of pre-eclampsia. Int J Gynaecol Obstet. 2016 Jul;134(1):62-5. PubMed PMID: 27113418. Epub 2016/04/27. eng.

63. Orchard TJ, Nathan DM, Zinman B, Cleary P, Brillon D, Backlund JY, et al. Association between 7 years of intensive treatment of type 1 diabetes and longterm mortality. Jama. 2015 Jan 6;313(1):45-53. PubMed PMID: 25562265. Pubmed Central PMCID: Pmc4306335. Epub 2015/01/07. eng.

64. Pare E, Parry S, McElrath TF, Pucci D, Newton A, Lim KH. Clinical risk factors for preeclampsia in the 21st century. Obstet Gynecol. 2014 Oct;124(4):763-70. PubMed PMID: 25198274. Epub 2014/09/10. eng.

65. Abalos E, Cuesta C, Carroli G, Qureshi Z, Widmer M, Vogel JP, et al. Preeclampsia, eclampsia and adverse maternal and perinatal outcomes: a secondary analysis of the World Health Organization Multicountry Survey on Maternal and Newborn Health. Bjog. 2014 Mar;121 Suppl 1:14-24. PubMed PMID: 24641531. Epub 2014/03/20. eng.

66. Rolnik DL, Wright D, Poon LC, O'Gorman N, Syngelaki A, de Paco Matallana C, et al. Aspirin versus Placebo in Pregnancies at High Risk for Preterm Preeclampsia. N Engl J Med. 2017 Aug 17;377(7):613-22. PubMed PMID: 28657417. Epub 2017/06/29. eng.

67. Adkins K, Allshouse AA, Metz TD, Heyborne KD. Impact of aspirin on fetal growth in diabetic pregnancies according to White classification. Am J Obstet Gynecol. 2017 Oct;217(4):465.e1-.e5. PubMed PMID: 28599894. Epub 2017/06/11. eng.

68. Lepercq J, Coste J, Theau A, Dubois-Laforgue D, Timsit J. Factors associated with preterm delivery in women with type 1 diabetes: a cohort study. Diabetes Care. 2004 Dec;27(12):2824-8. PubMed PMID: 15562192. Epub 2004/11/25. eng.

69. Ekbom P, Damm P, Feldt-Rasmussen B, Feldt-Rasmussen U, Jensen DM, Mathiesen ER. Elevated third-trimester haemoglobin A1c predicts preterm 
delivery in type 1 diabetes. Journal of Diabetes and its Complications. 2008 2008/09/01/;22(5):297-302.

70. Nielsen LR, Damm P, Mathiesen ER. Improved pregnancy outcome in type 1 diabetic women with microalbuminuria or diabetic nephropathy: effect of intensified antihypertensive therapy? Diabetes Care. 2009 Jan;32(1):38-44. PubMed PMID: 18945922. Pubmed Central PMCID: Pmc2606826. Epub 2008/10/24. eng.

71. Gutaj P, Wender-Ozegowska E. Diagnosis and Management of IUGR in Pregnancy Complicated by Type 1 Diabetes Mellitus. Curr Diab Rep. 2016 May;16(5):39. PubMed PMID: 26983627. Pubmed Central PMCID: Pmc4794518. Epub 2016/03/18. eng.

72. Ye M, Liu Y, Cao X, Yao F, Liu B, Li Y, et al. The utility of HbA1c for screening gestational diabetes mellitus and its relationship with adverse pregnancy outcomes. Diabetes Research and Clinical Practice. 2016;114:43-9.

73. Gomes MB, Coral M, Cobas RA, Dib SA, Canani LH, Nery M, et al. Prevalence of adults with type 1 diabetes who meet the goals of care in daily clinical practice: A nationwide multicenter study in Brazil. Diabetes Research and Clinical Practice. 2012 7//;97(1):63-70.

74. Hanson U, Persson B, Thunell S. Relationship between haemoglobin A1C in early type 1 (insulin-dependent) diabetic pregnancy and the occurrence of spontaneous abortion and fetal malformation in Sweden. Diabetologia. 1990 Feb;33(2):100-4. PubMed PMID: 2328844. Epub 1990/02/01. eng.

75. Moy FM, Ray A, Buckley BS, West HM. Techniques of monitoring blood glucose during pregnancy for women with pre-existing diabetes. Cochrane Database Syst Rev. 2017 Jun 11;6:Cd009613. PubMed PMID: 28602020. Epub 2017/06/12. eng.

76. Secher AL, Ringholm L, Andersen HU, Damm P, Mathiesen ER. The effect of real-time continuous glucose monitoring in pregnant women with diabetes: a randomized controlled trial. Diabetes Care. 2013 Jul;36(7):1877-83. PubMed PMID: 23349548. Pubmed Central PMCID: Pmc3687305. Epub 2013/01/26. eng. 77. Metzger BE, Lowe LP, Dyer AR, Trimble ER, Chaovarindr U, Coustan DR, et al. Hyperglycemia and adverse pregnancy outcomes. N Engl J Med. 2008 May 8;358(19):1991-2002. PubMed PMID: 18463375. Epub 2008/05/09. eng.

78. Stewart ZA, Wilinska ME, Hartnell S, Temple RC, Rayman G, Stanley KP, et al. Closed-Loop Insulin Delivery during Pregnancy in Women with Type 1 Diabetes. N Engl J Med. 2016 Aug 18;375(7):644-54. PubMed PMID: 27532830. Epub 2016/08/18. eng.

79. Chen R, Ben-Haroush A, Weismann-Brenner A, Weissman-Brenner A, Melamed N, Hod M, et al. Level of glycemic control and pregnancy outcome in type 1 diabetes: a comparison between multiple daily insulin injections and continuous subcutaneous insulin infusions. Am J Obstet Gynecol. 2007 Oct;197(4):404.e1-5. PubMed PMID: 17904979. eng. 